\title{
MATING SYSTEMS AND POPULATION STRUCTURE IN TWO CLOSELY RELATED SPECIES OF THE WHEAT GROUP I. VARIATION BETWEEN AND WITHIN POPULATIONS
}

\author{
JOSEPH HILLEL*, MARCUS W. FELDMAN* and GIORA SIMCHEN + \\ Department of Genetics, The Hebrew University, Jerusalem, israel, and \\ Department of Biology, Stanford University, Stanford, California
}

Received 6.iv.72

\section{Summary}

\begin{abstract}
Samples of seven wild populations of the predominantly selfing species Triticum longissimum were compared with samples of five populations of the closely related, but predominantly outcrossing species, $T$. speltoides. For most of the 36 quantitative characters which were examined, the differences between populations, the total variances of the populations and the mean within-family variances, were greater in the selfer than in the outbreeder. Theoretical models were analysed in an attempt to explain these results, using concepts of classical population genetics.
\end{abstract}

\section{INTRODUCTION}

THE existence of substantial genetic variability in predominantly selfpollinating species of plants has been known since the earliest days of cultivation. Only in recent years has the naturally occurring variability in such species been evaluated and quantified (e.g. Weil and Allard, 1964; Allard, 1965; Imam and Allard, 1965; Moore and Lewis, 1965; Allard, Jain and Workman, 1967; Jain and Marshal, 1967; Antonovics, 1968; Pederson, 1968; Jain, Marshal and Wu, 1970; Jones, 1971a,b).

The genetic variability within species can be partitioned into several components: variance between populations within a species, variance between families within the population and variance arising from the differences between individuals within families. One of the objects of the analysis of these effects in samples originally collected in the wild is to make inferences on the possible selective regimes experienced by the wild population.

The analysis of possible mechanisms for preserving variability is concomitant to the analysis of variability itself. Conservation of variability in inbreeding systems by means of selection has been discussed by Hayman (1953), Hayman and Mather (1953), Allard et al. (1967) and Karlin (1968). The significance of linkage and its possible interaction with selection in conserving variability was pointed out by Lewis and John (1963), Parsons (1957), Jain and Allard (1966), Allard et al. (1967) and Karlin (1968). The mating system itself is one of the crucial determinants of the degree of variability but, as the above-named authors have pointed out, its effects can be overwhelmed by, for example, selection.

Since it is reasonable to assume that the amount of gene flow between populations of selfing species is smaller than in outbreeders, we can predict greater differences between populations of the selfing species than between populations of the outbreeder. That such is the case has been demonstrated by Knowles (1943) in Bromus mollis, Weil and Allard (1964) in Collinsia

* Research supported in part by National Institute of Health Grant USPHS 10452-09.

$\dagger$ Present address: Laboratory of Applied Genetics, Hebrew University, Rehovot, Israel. 
heterophilla, Imam and Allard (1965) and Jain and Marshal (1967) in Avena fatua and $A$. barbata, Antonovics (1968) in Agrostis tenuis and Anthoxanthum odoratum, and Jones (1971 $a$ ) in Arabidopsis thaliana. The same isolation effect might, on the other hand, be expected to produce significant differences between families within populations of a predominantly selfing species (Knowles, 1943; Lawrence, 1969; Jain et al., 1970; Jones, 1971b). Allard et al. (1967) have remarked, "Individuals within a population are often heterozygous for many genes governing quantitative characters. The variability that is commonly observed within individual families is therefore not exclusively environmental but much of it can be ascribed to segregation. It is clear that the genetic organisation of a population cannot be determined solely from the rate of outcrossing that occurs in the population." The experiments to be reported here further emphasise the truth of this statement.

The above-mentioned studies of the genetic variances in selfing species demonstrated the presence of variation between and within populations where selfing is the predominant mating system. These studies do not and cannot examine the direct effect of the mating system on the amount of genetic variation. We believe that such an evaluation can be done by comparing two closely related species which differ in their mating system. Such pairs are not common.

The genus Triticum-Aegilops (Bowden, 1959; Chennaveeraiah, 1960; Morris and Sears, 1967; MacKey, 1968; Sears, 1969) consists of species at various levels of ploidy. These species are indigenous to an extended area in western and central Asia (Zohary, 1966). Among the diploid species $(2 n=14)$ there are two closely related species, namely Triticum longissimum (= Aegilops longissima) and T. speltoides (= Ae. speltoides) which seem to be morphologically very similar. The former, however, is predominantly a selfer while the latter is predominantly an outcrosser. The physiology of the flowering of $T$. longissimum appears to preclude all but rare outcrossing events (Zohary and Imber, 1963); Simchen, Zarchi and Hillel, 1971). The mature anthers open and discharge most of the pollen grains within the floret before emerging from it. This process ensures that self-pollination occurs although the actual proportion of selfing as against outcrossing has not been measured. In $T$. speltoides, on the other hand, the anthers emerge from the florets still unsplit. From progeny tests, Zohary and Imber (1963) have estimated the extent of outcrossing in populations of $T$. speltoides to be 75 to 95 per cent. It should be noted that, although this examination has been carried out for several populations of $T$. speltoides, not all of the populations considered in this paper were represented. One should also bear in mind that Zohary and Imber tested their populations more than six years before our experiments. In the series of experiments reported here our object was to compare populations of these two species with respect to quantitative characters and relate the differences between them to the mating system and other possible evolutionary factors.

\section{Materials AND methods}

\section{(i) Population survey}

Seven populations of $T$. longissimum and five of $T$. speltoides were sampled from various sites in Israel. Table 1 and fig. 1 summarise the locations and prevailing environmental conditions for the 12 populations. 


\section{(ii) Experimental design}

Ten spikes, each from a different plant, were sampled at random from each of the 12 natural populations. Each spike was used to establish a family, consisting of four offspring from the same mother plant, in the following manner. The seeds from each family (i.e. spike) were sown in a common petri dish in the laboratory on 8th October 1969. Germination was completed 5 days after sowing, at which stage four seedlings were sampled at

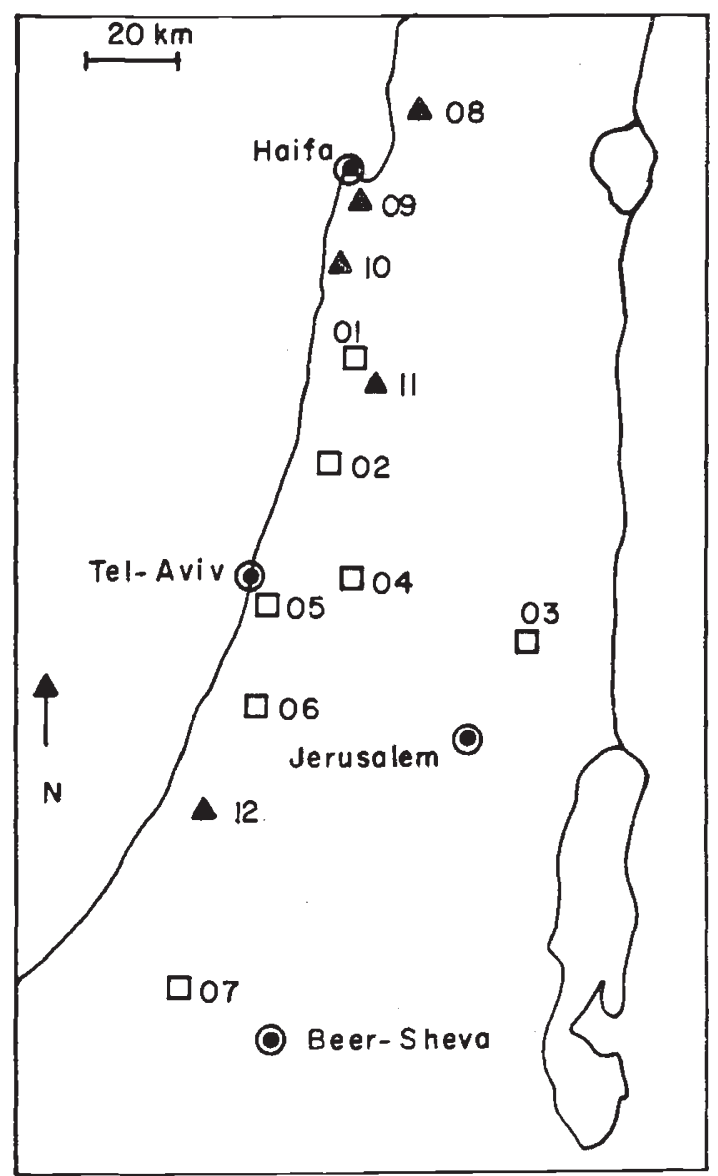

Fig. 1.-Approximate locations of the populations: Populations of $T$. longissimum (1-7) are represented by squares and the populations of $T$. speltoides (8-12) are represented by triangles. (Reprinted from Zarchi et al., 1972.)

random from each petri dish (i.e. family). The seedlings were randomly allocated to peat flower-pots in a wire-mesh-covered house.

Seventy days later the pots were moved to experimental plots at the Talpiot experimental farm in Jerusalem. The field was divided into two blocks. Two seedlings were allocated randomly to each block. In this way the members of each family were allocated randomly to each block so that randomisation was complete. The two marginal rows in both sides of each 

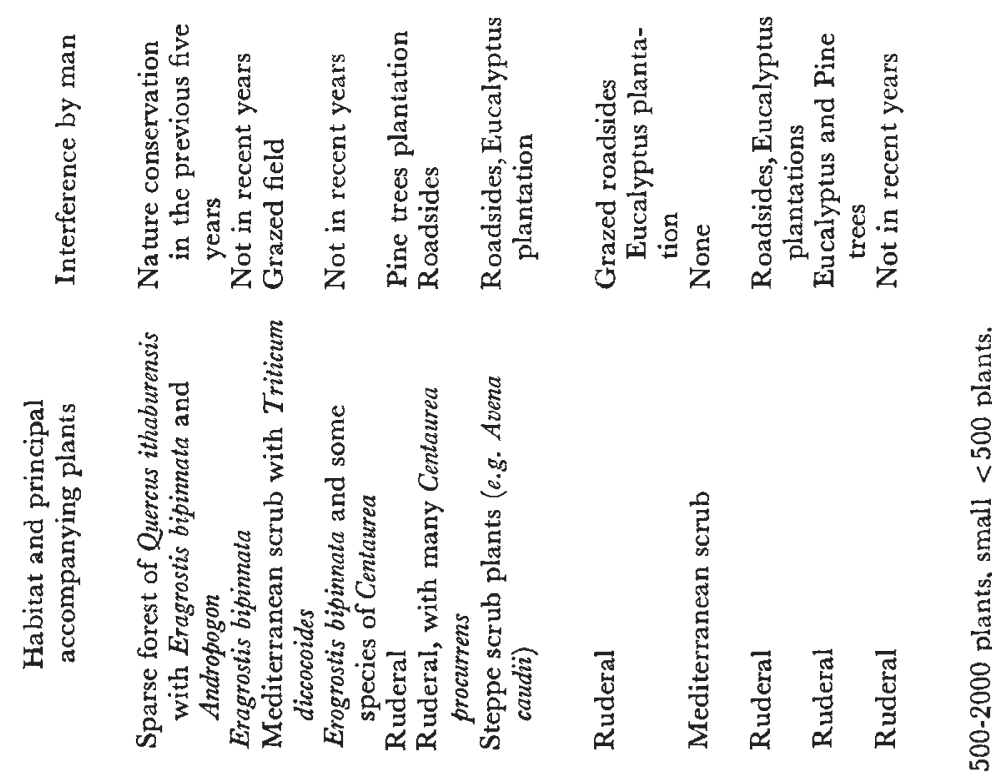

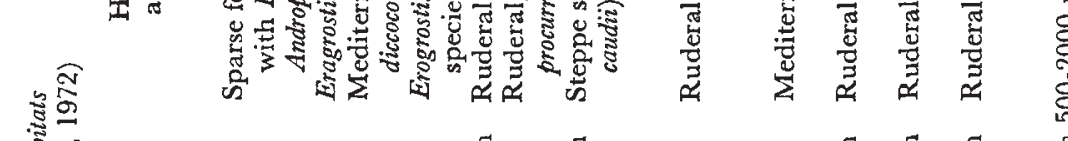

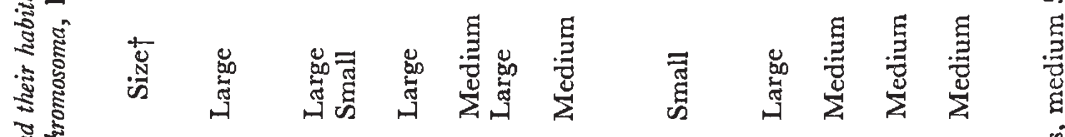

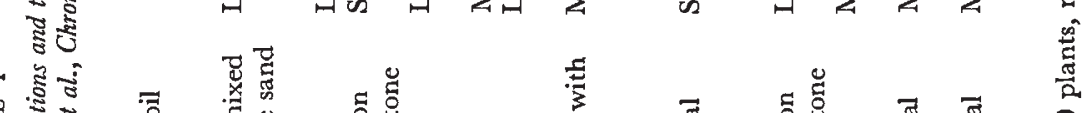

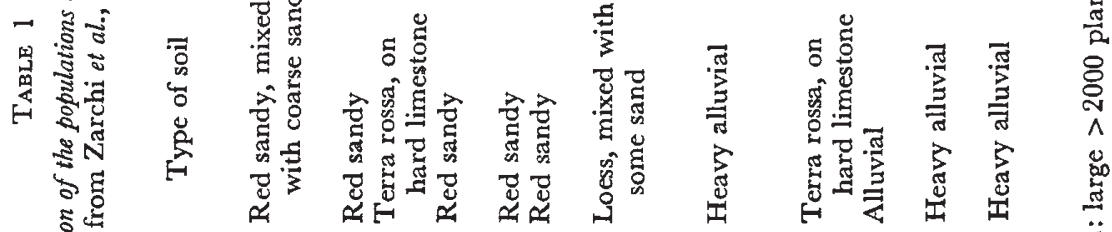

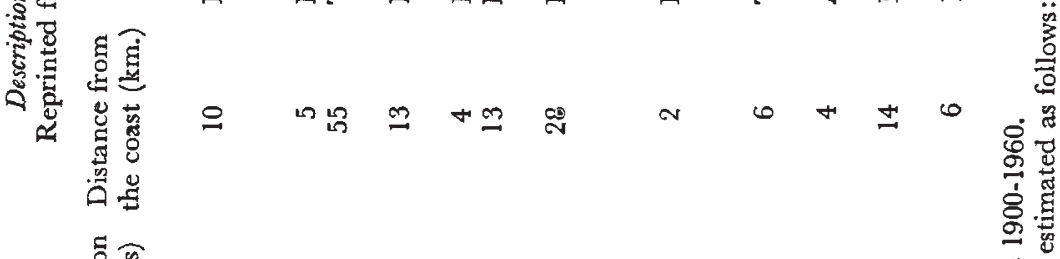

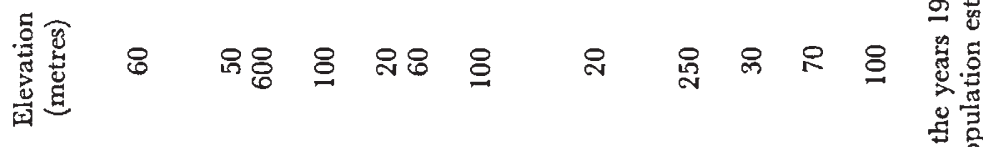

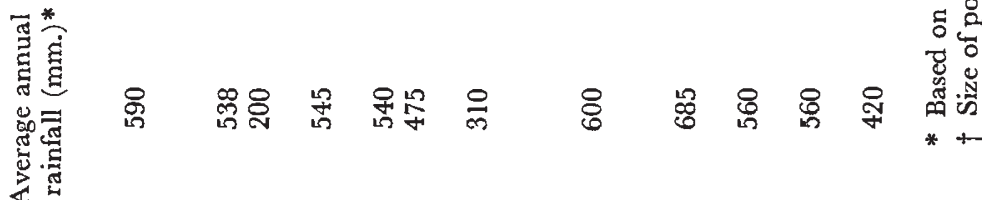

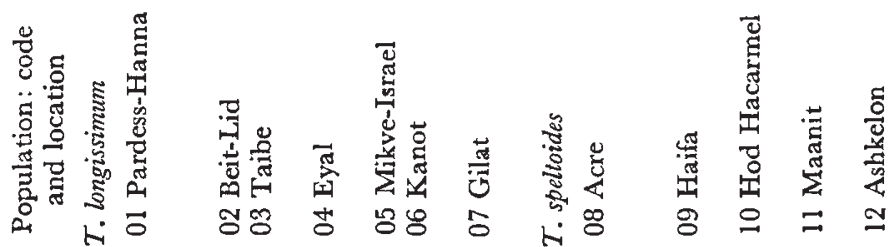


block were guards, as were the two end plants in each row. The distance between plants in the field were $1.5 \times 0.5$ metres. This generation of plants we called $S_{0}$.

The same procedure was carried out for another set of seeds obtained by selfing the progeny of seed taken from the wild in 1968. This generation we called $S_{1}$. Both $S_{0}$ and $S_{1}$ were randomised and grown together in the same blocks. In all that follows, unless the $S_{1}$ generation is referred to specifically, we are considering the $S_{0}$ generation.

\section{(iii) Description of characters}

Forty measurements were made on each plant during the experiment. Thirty-six of them are detailed in tables 2-6. Germination and chiasma characteristics will be considered separately (Hillel, unpubl.; Zarchi, Simchen, Hillel and Schapp, 1972). The number of leaves and tillers of the plants at 2 weeks of growth are not reported since they showed no interesting properties. Gharacters 21, 22, 23 and 24 are measured on a scale of five points. Thus for character 2l, which measures the erectness of the plant, 1 represents the most horizontal while 5 represents fully erect plants. For character 22, green-coloured plants are denoted by 1 and fully violet plants by 5 . For character 23, juicy plants are indicated by 1 and dry plants by 5 . For character 24, normal emergence of the spikes through their sheath is denoted by 1 and those encountering the most difficulty in emergence were indicated by 5 .

Heading and flowering time (characters 1-3 and 5-7) were measured for the first three spikes as the number of days from the arbitrary date, lst March. The range from the first to the third headings and flowering times (characters 4 and 8 ) were computed directly from characters 1-3 and 5-7, respectively. The ranges between heading and flowering for each of the first three spikes were also calculated directly from 1-3 and 5-7. Total tiller height without awns and height without spikes were measured for the first three flowered spikes at the flowering time (character 12-17) and again at harvesting time (characters 25-30). Spike length (characters 18-20) was computed by subtracting the total without spike from the total height.

\section{Results}

\section{(i) General}

Table 2 summarises the complete analysis of variance for the nested design and consists of the $F$ ratios, for the differences between species, between populations within species and between families within populations. Since the differences between the two blocks and the block $\times$ family interaction in each of the 12 populations were insignificant for the various measurements, we tested the significance of the between-families mean squares against the within-families mean squares. In 24 out of the 36 traits the individual differences between the species were not significant. The 12 characters which showed significant differences between the species were those connected with the seed production and dispersal unit, namely, spike length, number of spikelets in a spike, spike weight of the first three spikes, and the difficulty of spike emergence. Colour and erectness were significant 
TABLE 2

Analyses of variance: F ratios of the total analysis for measurements

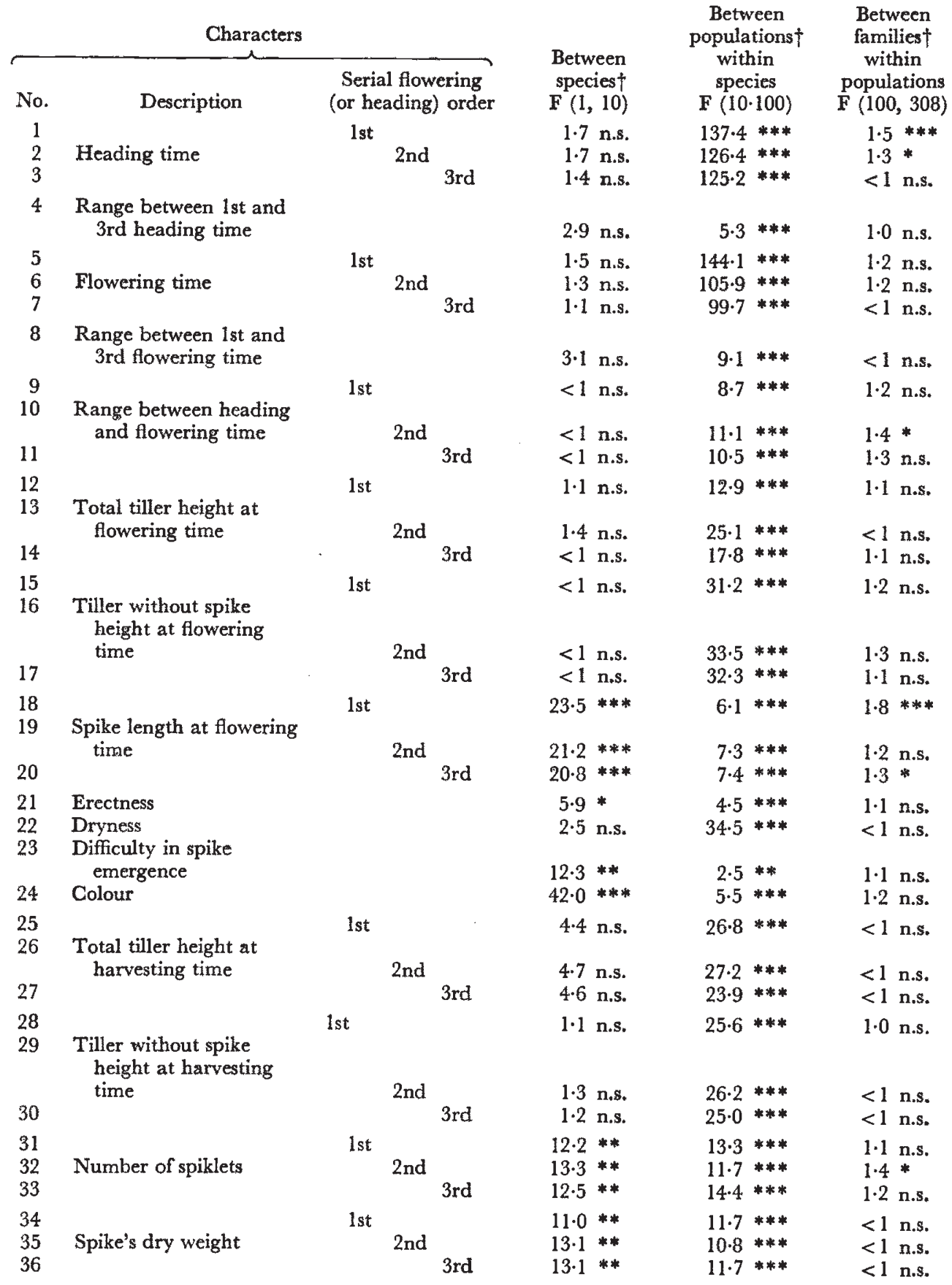

$\dagger$ Population 3 has not measured for flowering time, thus the degrees of freedom for characters 5-11 will be as follows:

Description
Heading time
Range between 1st and
3rd heading time
Flowering time
Range between 1st and
3rd flowering time
Range between heading
and flowering time
Total tiller height at
flowering time
Tiller without spike
height at flowering
time

Between species

(b) Between populations within species $=9$.

(c) Between families within populations $=97$.

(d) Within families $=267$.

n.s. $=$ Non-significant difference.

* = Difference significant $0.01<P \leqslant 0.05$.

$* *=$ Difference significant $0.001<P \leqslant 0.01$.

*** $=$ Difference significant $\mathrm{P}<0.001$. 
also. That 24 characters showed no significant differences between species further attests to the similarity of the two species.

In every character there were differences between populations within species. The largest differences were found among the populations of T. longissimum.

Thirty of the 36 characters showed no significant differences between families within the 12 populations.
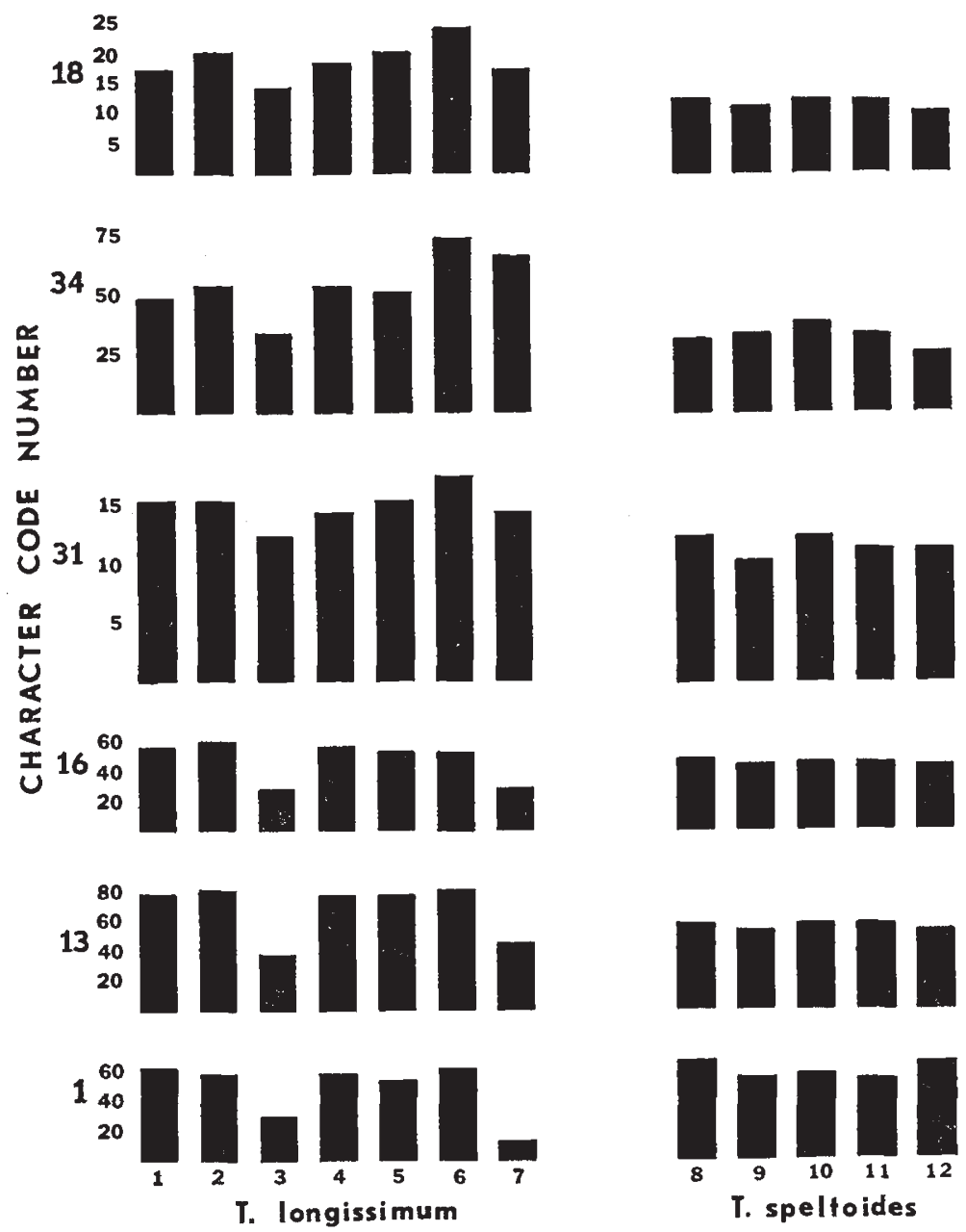

\section{POPULATION CODE NUMBER}

Fig. 2.-Means of the populations of $T$. longissimum and $T$. speltoides for six characters.

(ii) Differences between populations within each species

From tables 3 and 4 and fig. 2 it can be seen that the differences between

$T$. longissimum populations are higher than those between the populations of

$T$. speltoides. In nine characters there were no significant differences between 


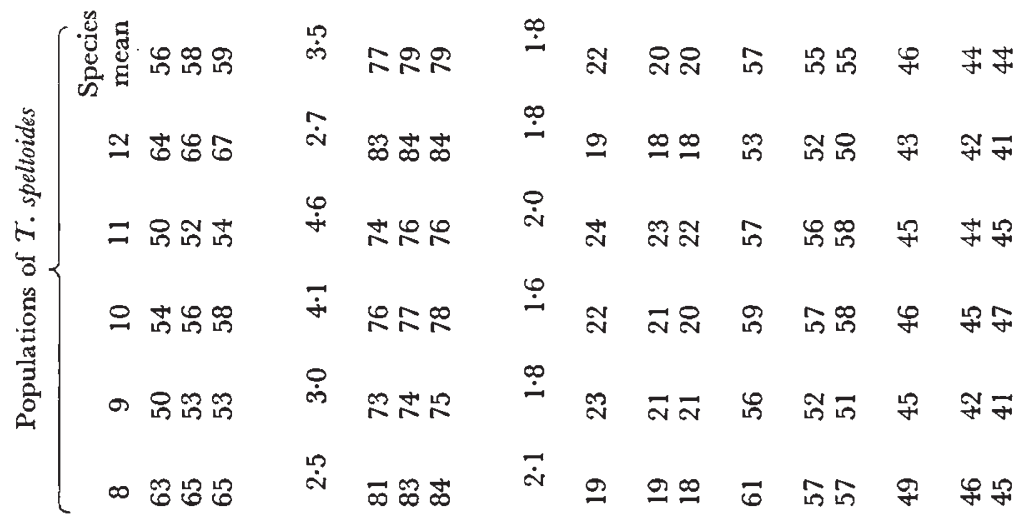

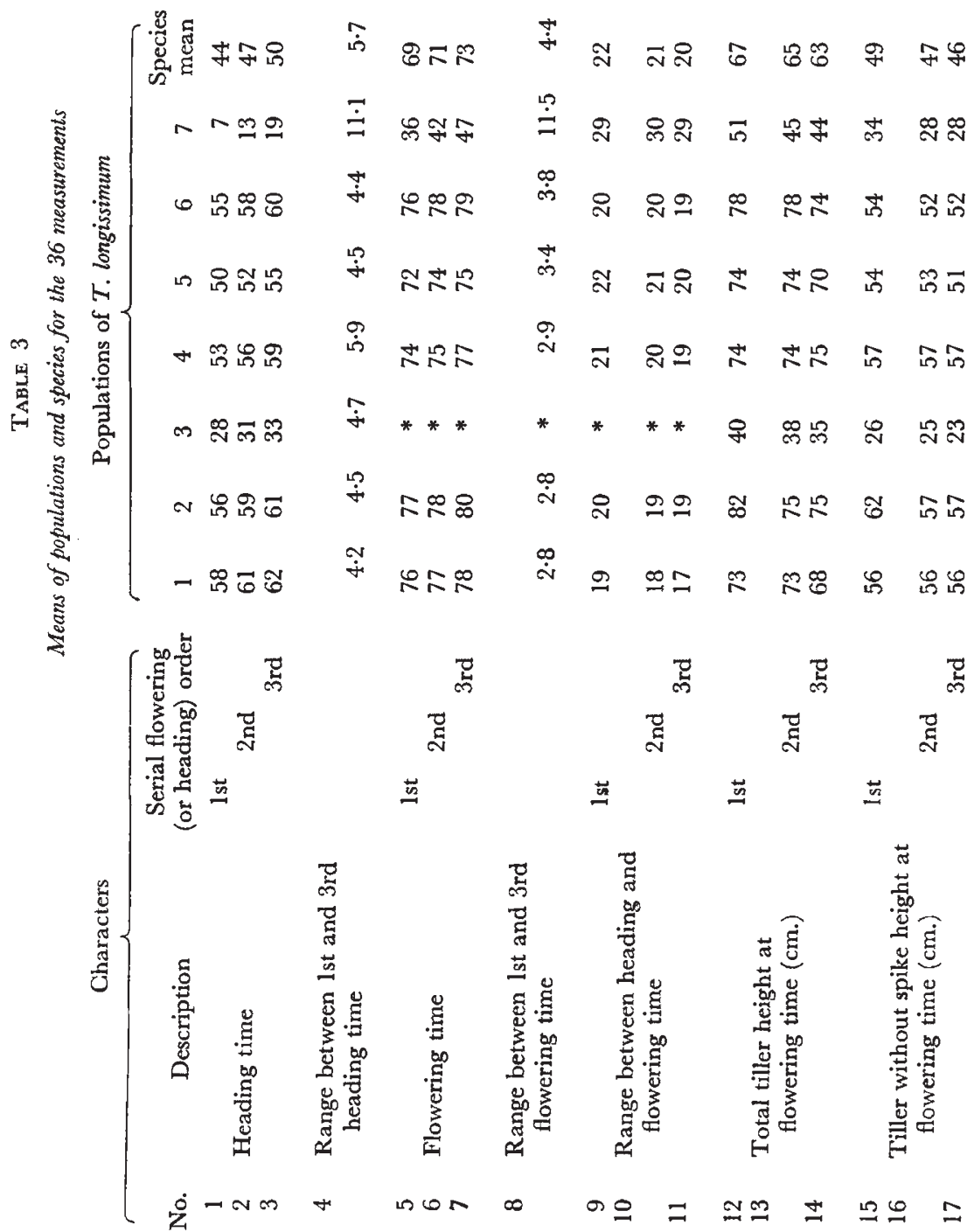


COMPARISONS OF RELATED WHEAT SPEGIES

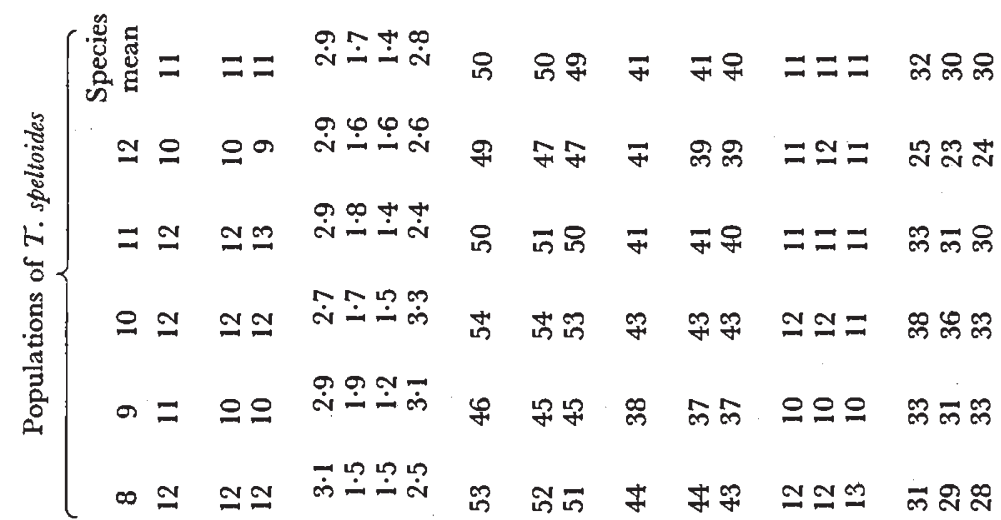

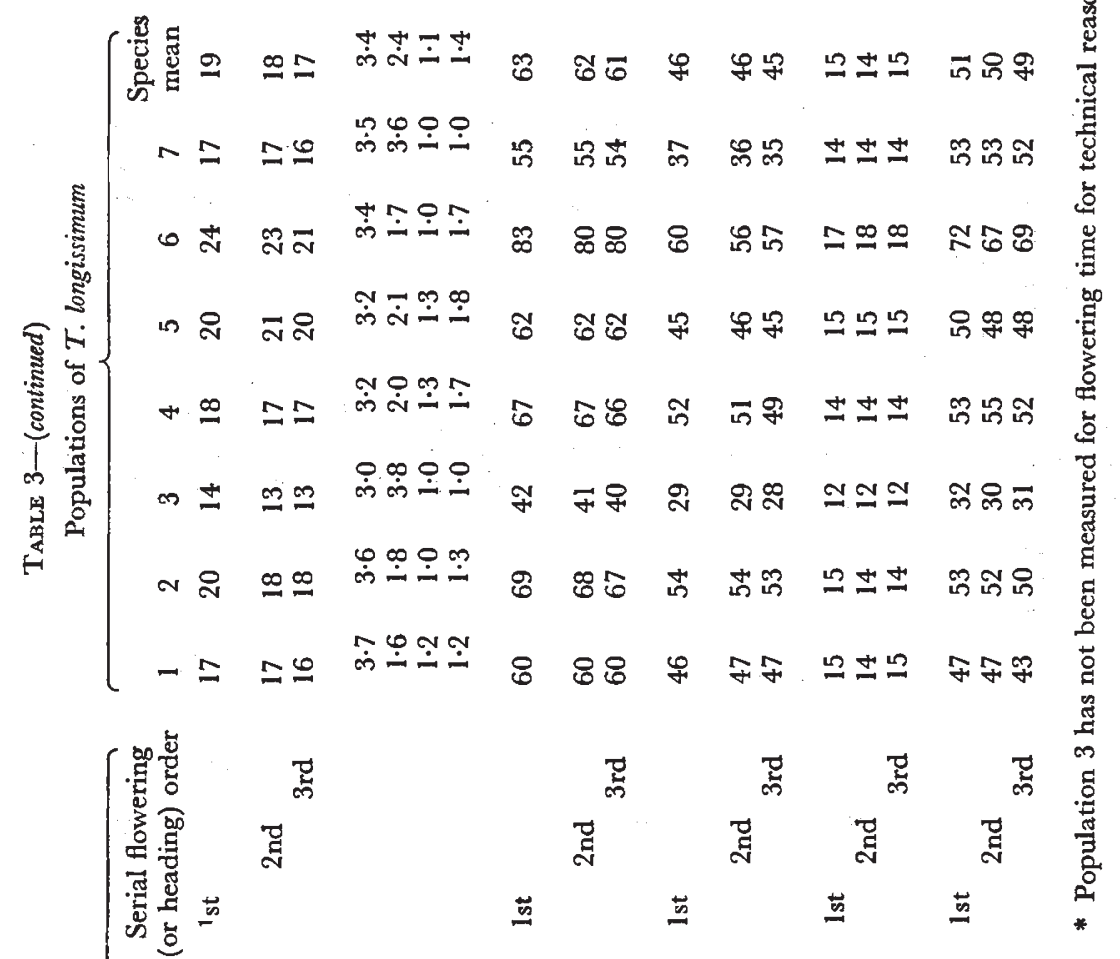
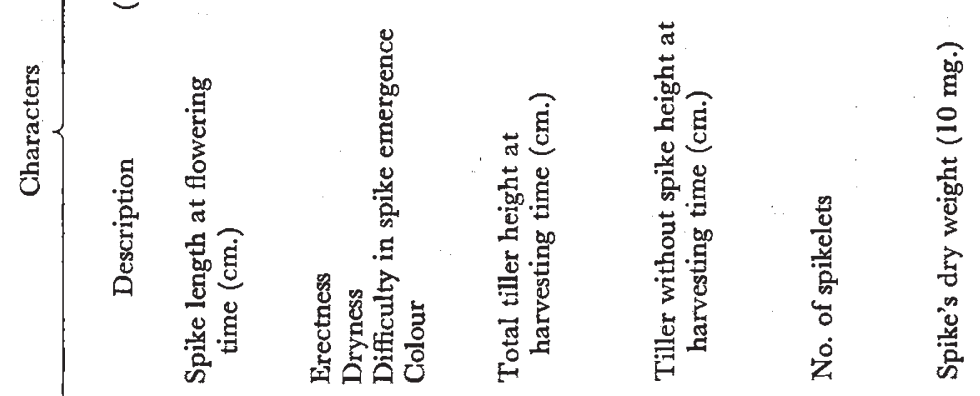

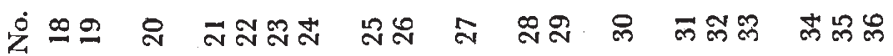
$30 / 2-\mathrm{K}_{2}$ 


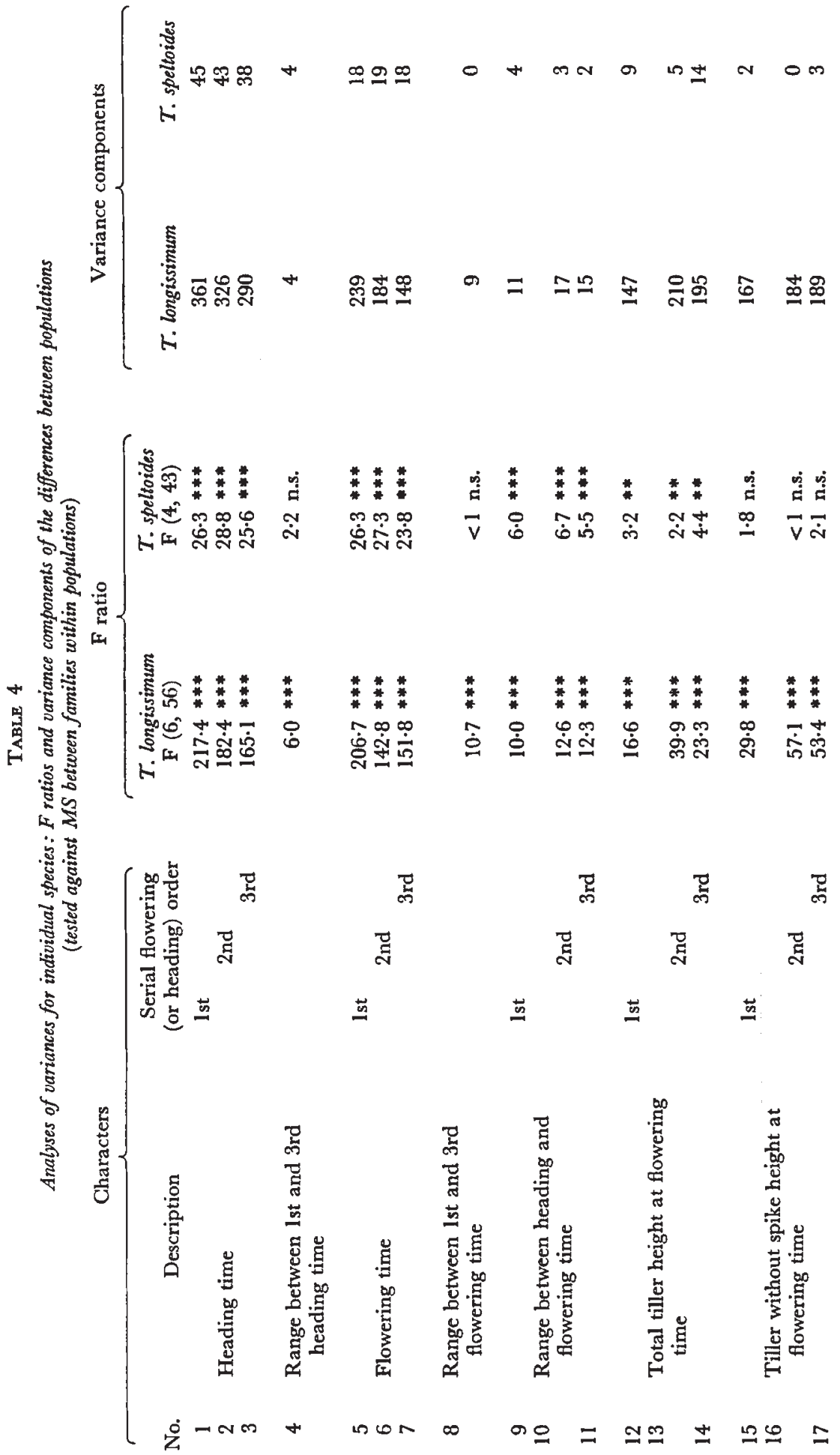


GOMPARISONS OF RELATED WHEAT SPEGIES

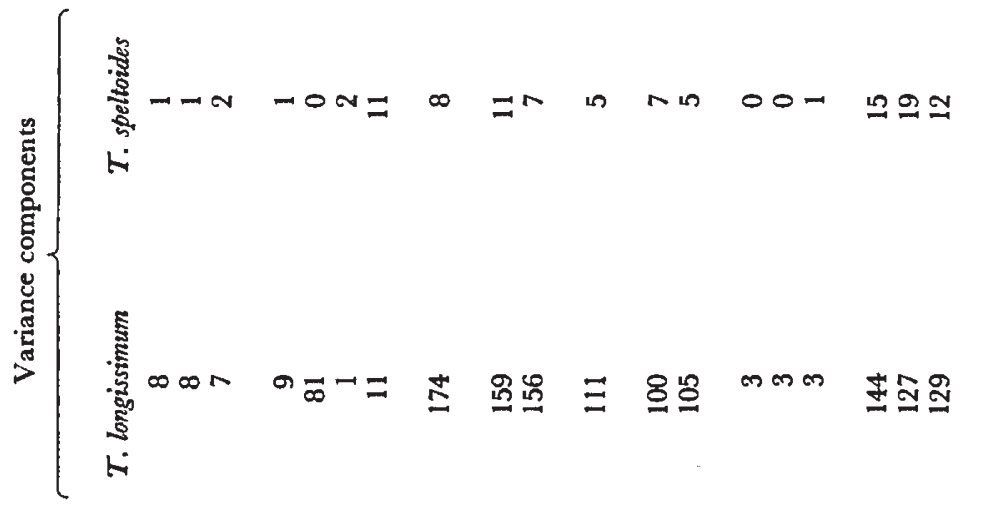

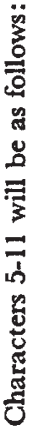

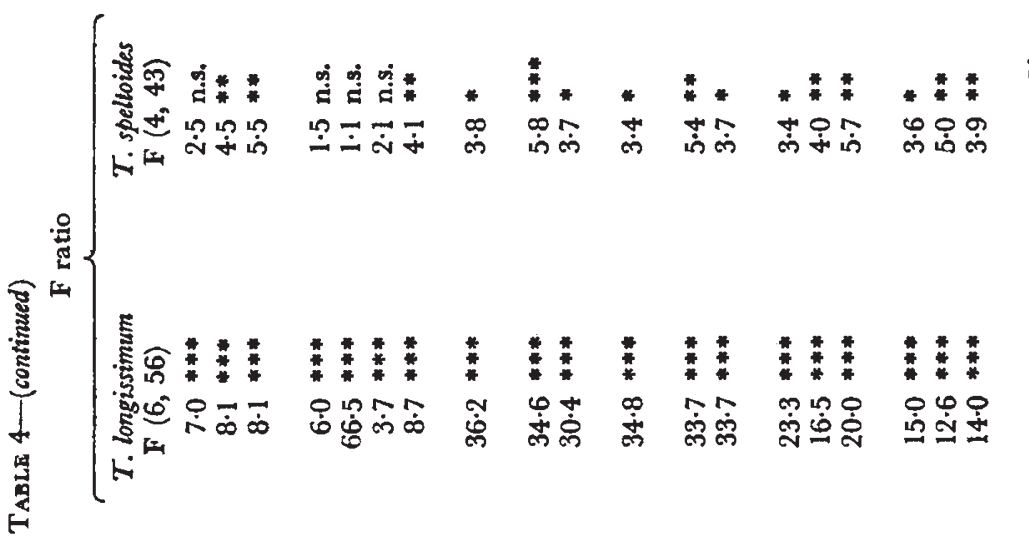

是
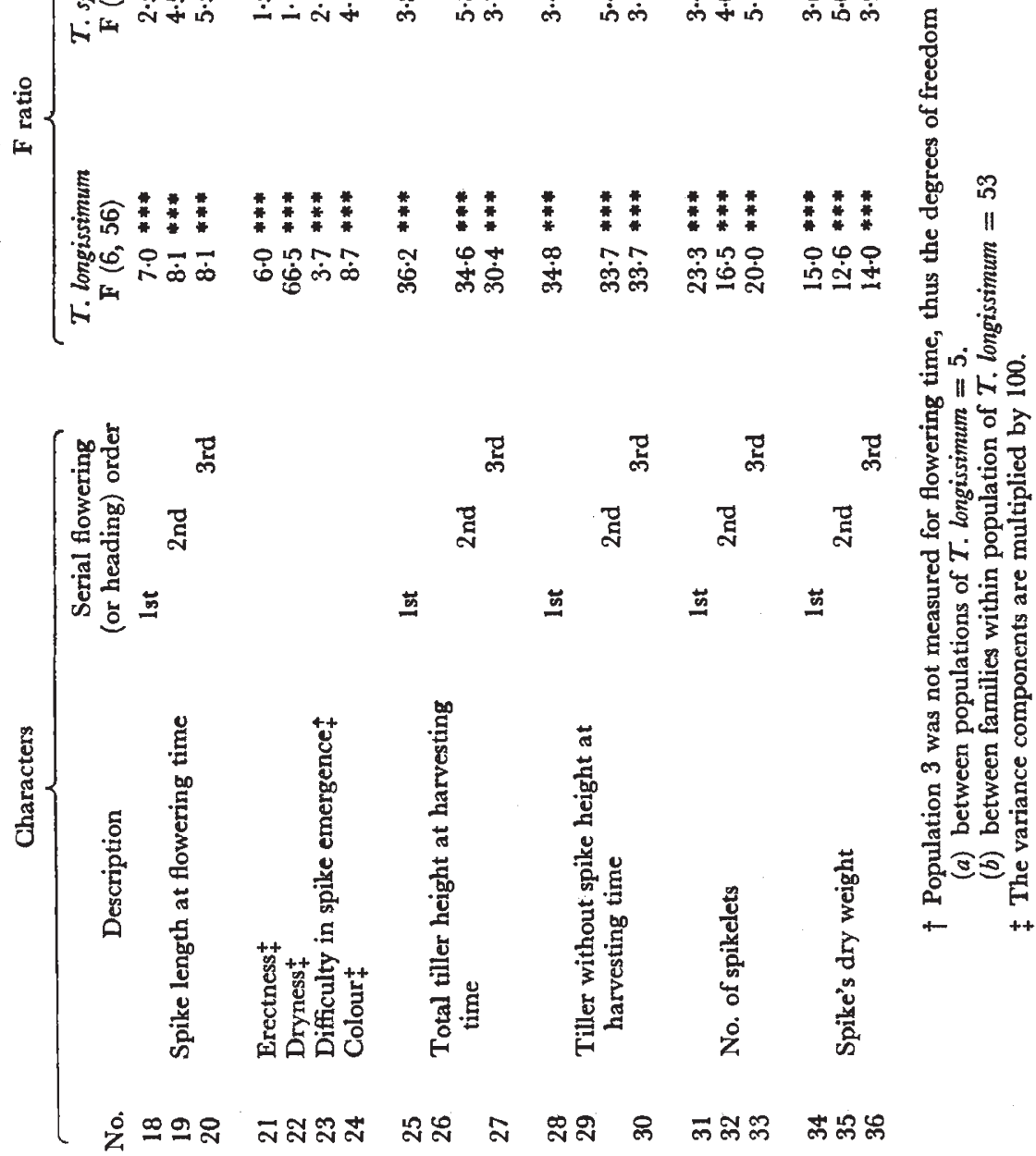
the five populations of $T$. speltoides while for all 36 characters the betweenpopulations variance of $\mathcal{T}$. longissimum was significant. Thus more characters in the selfer $T$. longissimum produced significant variances, and the variance components due to differences between populations within each species were higher in T. longissimum than in T. speltoides. It should be noted that in some characters the main contribution to the differences among the populations of $T$. longissimum arises from the difference between populations 7 and 3 and the other populations (e.g. character 1, 13, 16; see table 3 and fig. 2 and the discussion).
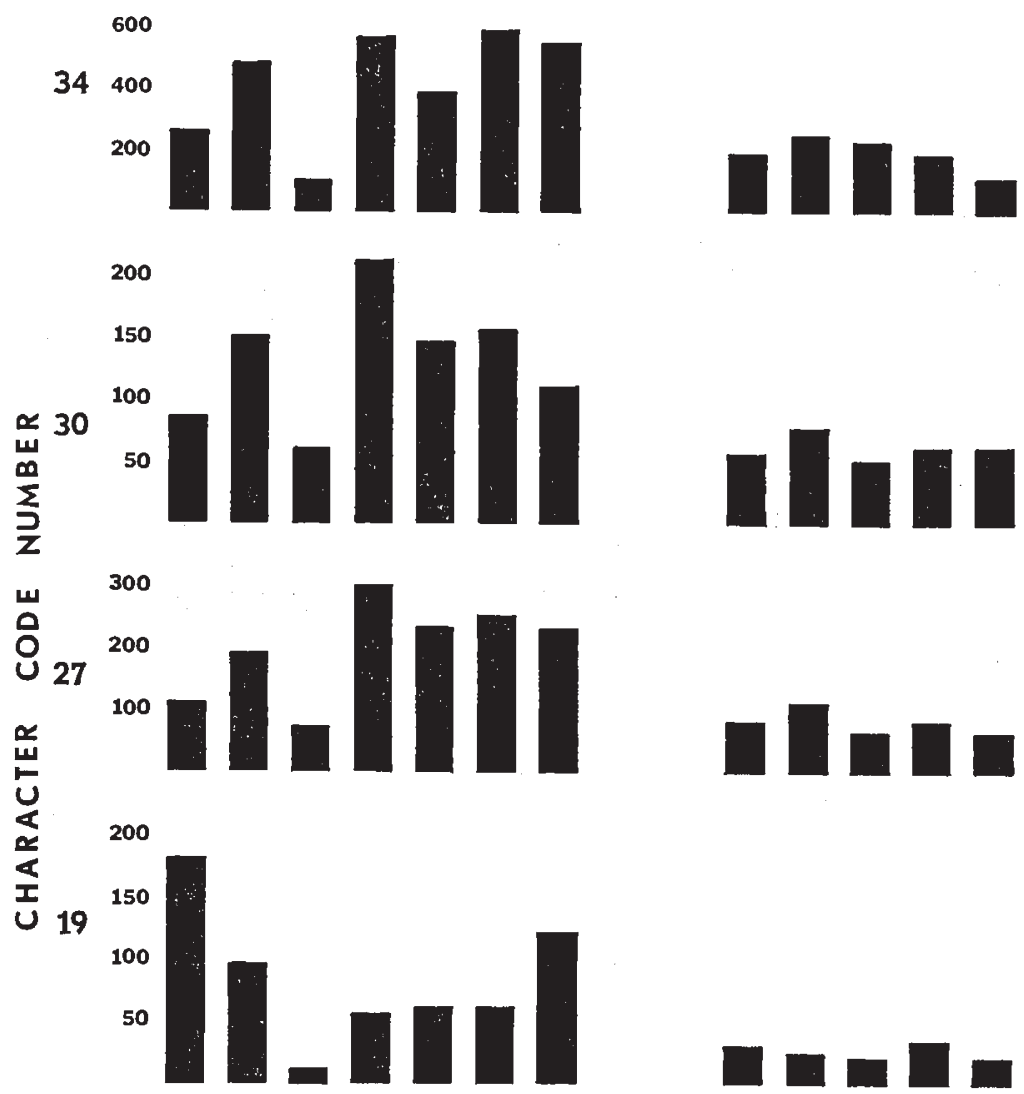

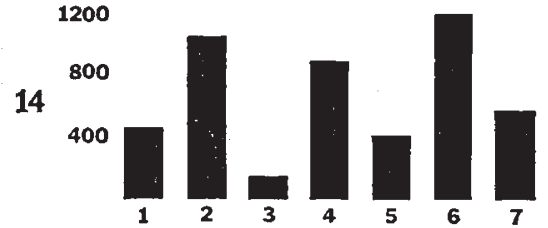

T. longissimum

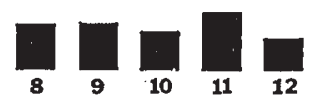

T. spelfoides

\section{POPULATION CODE NUMBER}

Frg. 3.-Variances within populations of $T$. longissimum and $T$. speltoides for five of the characters. 


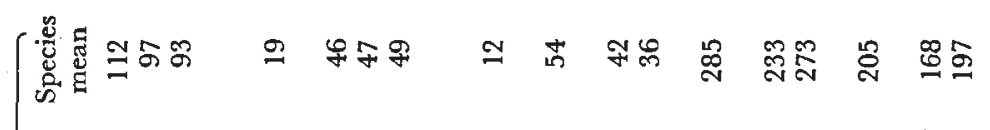

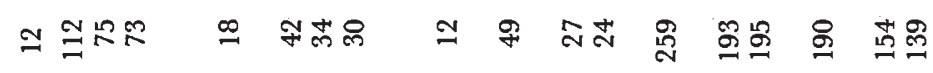

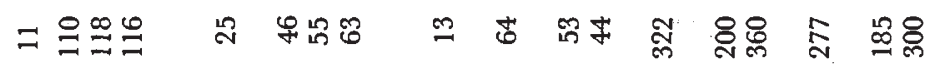

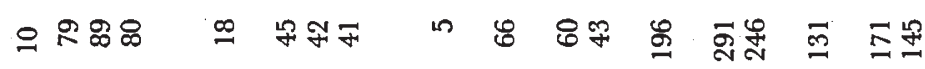
の $\stackrel{\infty}{=} \cong$

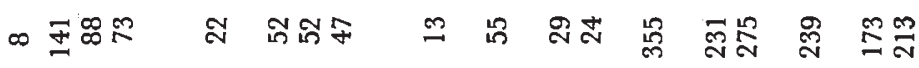

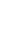

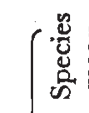

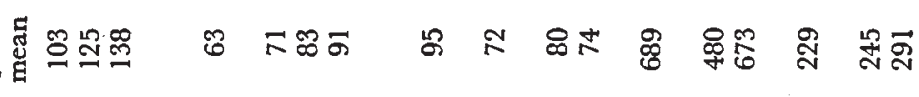

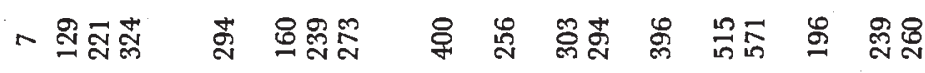

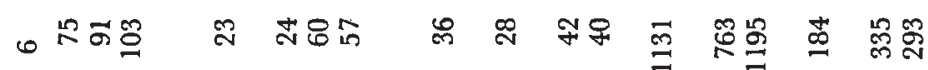

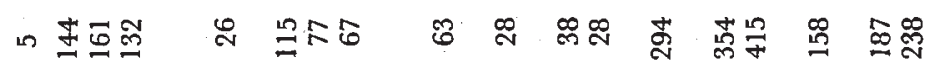

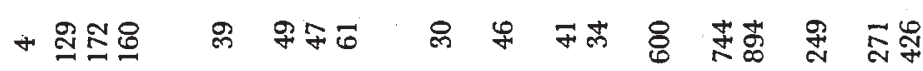

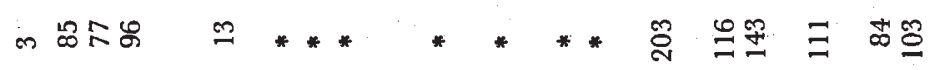

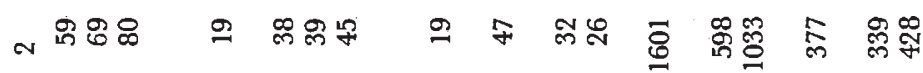

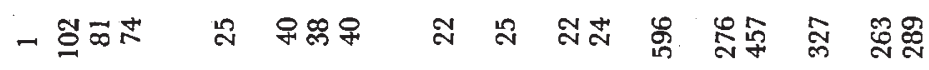

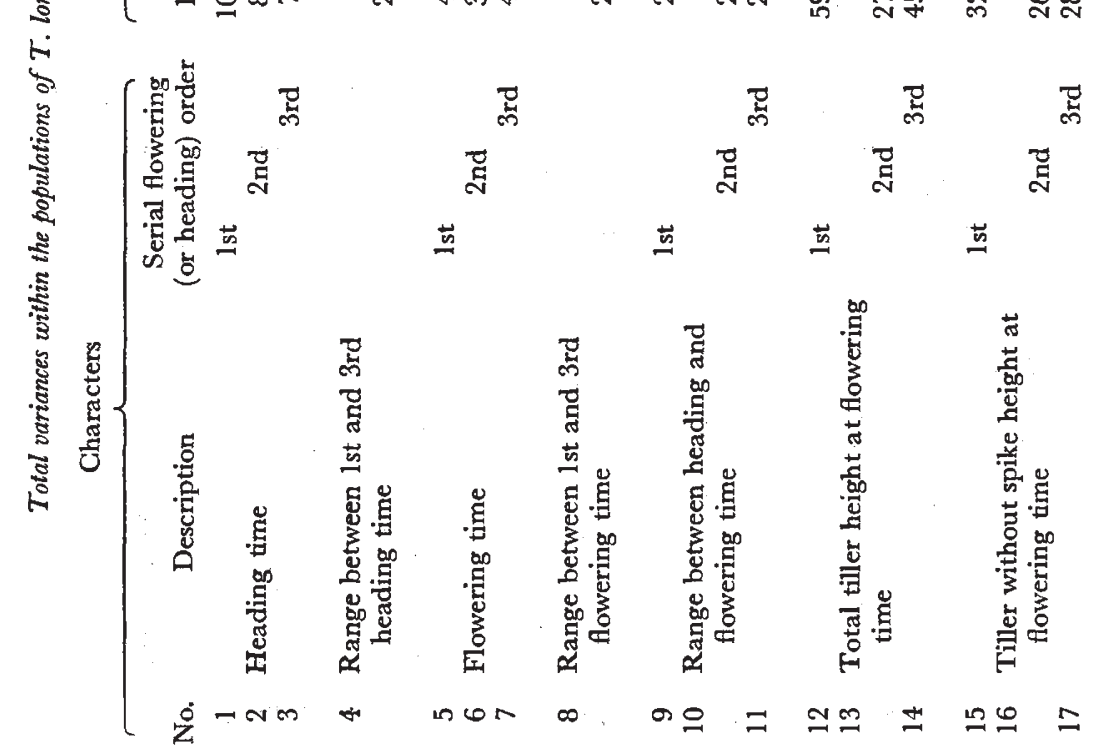




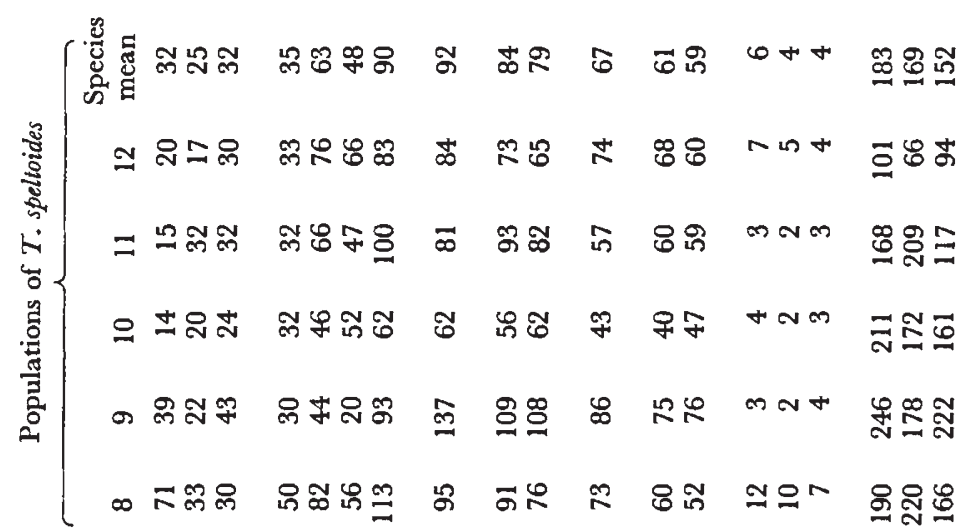

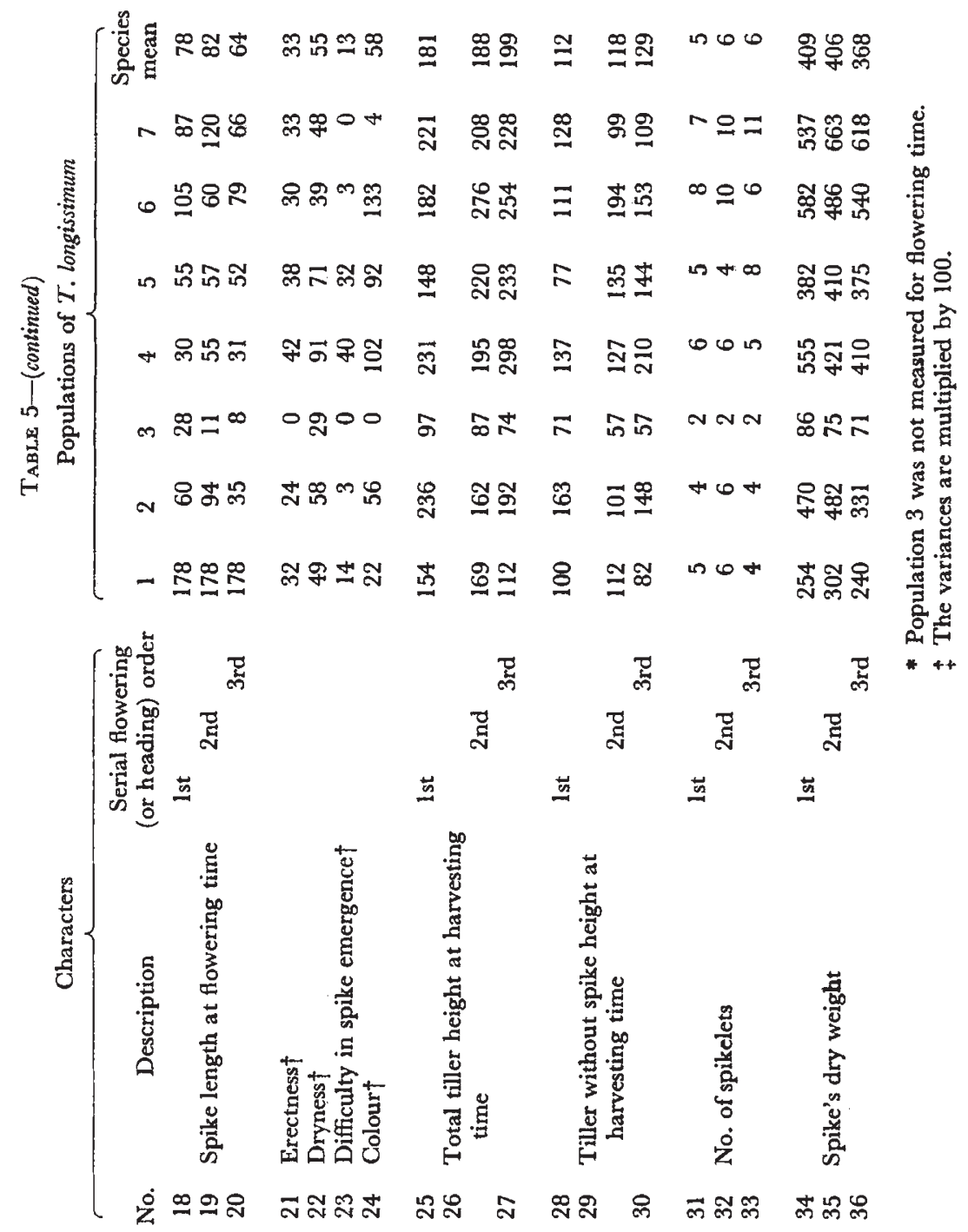




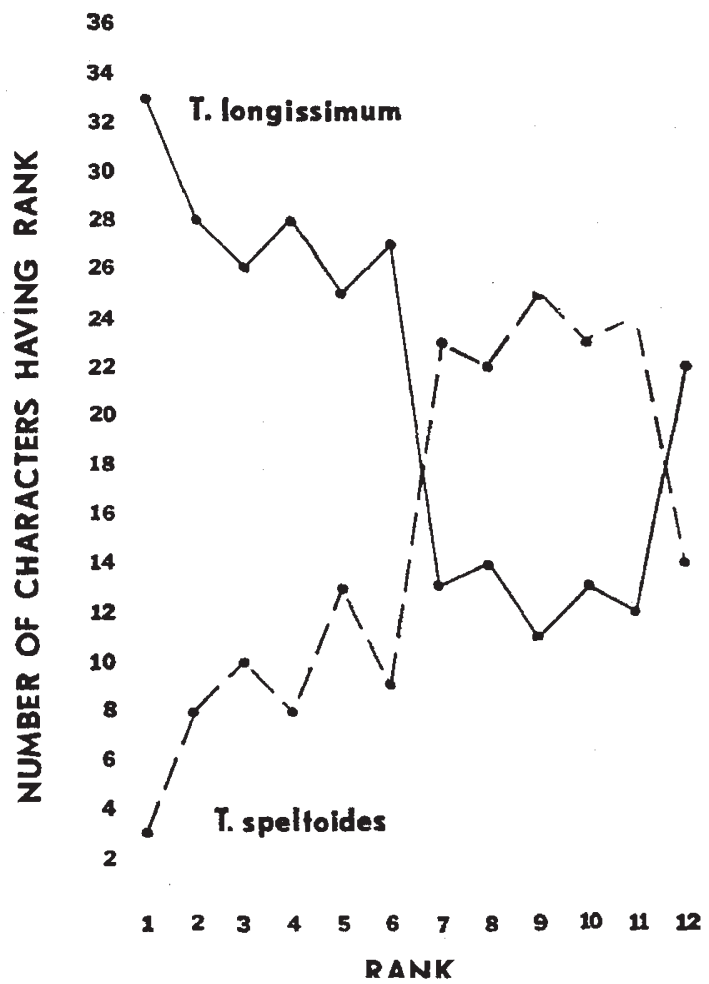

Frg. 4.-Summary of ranking of population variances for all 36 characters.

(iii) Within-population variances

Table 5 summarises the total variance within each of the 12 populations for each of the 36 characters. It can be seen that for most of the characters T. longissimum shows more variability except in population 3, which demonstrates the lowest variability in most of the traits. This point is discussed later. Fig. 3 exhibits the five extreme characters in which the populations of $T$. longissimum have the most variability. There seems to be homogeneity of variances between the $T$. speltoides populations but not in $T$. longissimum.

In order to exhibit more clearly the overall picture we have included fig. 4, which indicates the number of characters (on the ordinate) whose variance has the rank specified (on the abscissa) with 1 indicating highest and 12 the lowest ranking. Thus $T$. longissimum is seen to produce the highest ranks for most characters and $T$. speltoides the lower ranks. If there were no differences between the species we would expect to find 21 of the characters of $T$. longissimum at each rank $(36 \times 7 / 12)$ and 15 of $T$. speltoides. The deviations as shown in fig. 4 were highly significant $\left(\chi_{11}^{2}=32, \mathrm{P}<0.001\right)$. The reversal at ranks 11 and 12 is due to the anomolous behaviour of population 3. This is discussed later.

(iv) Within-family variances

The results of the within-family variances are summarised in table 6 . Six characters with the most extreme results are exhibited in fig. 5. From these results we can conclude: 


\begin{tabular}{|c|c|c|c|c|c|c|c|c|c|c|c|}
\hline & 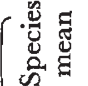 & 아용 & $\dot{\sigma}$ & $\stackrel{+}{\dot{\sim}} \dot{\dot{\sim}} \dot{\vec{\sim}}$ & $\stackrel{0}{\dot{0}}$ & $\stackrel{n}{\dot{I}}$ & 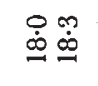 & $\widehat{a}$ & $\mathscr{\infty} \cong$ & $\stackrel{8}{\circ}$ & பేळ \\
\hline. & $\cong$ & พัฒั & $\ddot{\theta}$ & $\dot{\dot{t}} \dot{\Xi} \dot{\Xi}$ & $\dot{m}$ & 蒿 & 官宅 & 8 & 농요 & 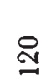 & $\therefore \overline{6}$ \\
\hline$\dot{H}$ & $=$ & 网出的 & $\stackrel{\varphi}{\ddot{m}}$ & 完市 $\stackrel{\phi}{\dot{N}}$ & $\hat{\text { in }}$ & $\stackrel{+}{\dot{N}}$ & 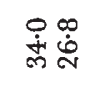 & 뇽 & $\Xi \hat{6}$ & $\stackrel{9}{\Xi}$ & P8 \\
\hline . & 익 & ஜூల్ & $\underset{\dot{\theta}}{\mathscr{0}}$ & 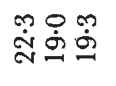 & $\hat{\dot{m}}$ & $\dot{ \pm}$ & 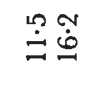 & 吕 & $\infty \Xi$ & $\widetilde{\infty}$ & $\widehat{6} \infty$ \\
\hline 。ํ. & $\sigma$ & テテพ & $\stackrel{\leftrightarrow}{\sim}$ & 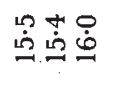 & $\stackrel{\varphi}{\infty}$ & $\stackrel{+}{\dot{a}}$ & $\stackrel{+}{\stackrel{\sim}{\Delta}}$ & $\stackrel{\varrho}{\exists}$ & 吅夠 & $\hat{\sigma}$ & ถู่อํำ \\
\hline & $\infty$ & ミ㕣禾 & 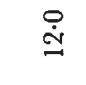 & 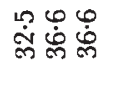 & $\ddot{\infty}$ & $\stackrel{\sim}{\grave{\hat{v}}}$ & 官曷 & 吉 & $\mathscr{\infty}$ & $\stackrel{12}{=}$ & $\leqslant \mathscr{R}$ \\
\hline & 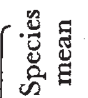 & テロ & $\stackrel{\text { ตे }}{\text { ตे }}$ & 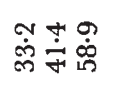 & $\stackrel{\varphi}{\dot{6}}$ & $\overrightarrow{\dot{m}}$ & 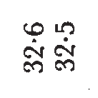 & 衰 & 品 & $\stackrel{\circ}{\circ}$ & I̊ \\
\hline & $n$ & 남을 & 总 & 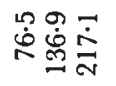 & $\begin{array}{l}\stackrel{+}{0} \\
\dot{d} \\
\text { N }\end{array}$ & $\overrightarrow{\dot{\grave{g}}}$ & 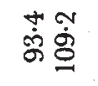 & $\underline{6}$ & ڤึ: & 苍 & $\underset{N}{\beth}$ \\
\hline · है & 0 & 웅 & $\stackrel{\sim}{\dot{\Xi}}$ & क̊용 & 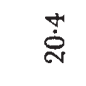 & $\ddot{\sigma}$ & $\overrightarrow{\dot{m}} \dot{\tilde{N}}$ & ஜ्లి & 怘学 & ஜ & ণ్రి \\
\hline H & $n$ & 188 & $\ddot{\Xi}$ & 它岀品 & m & $\stackrel{+}{\stackrel{\Delta}{N}}$ & $\mathcal{O} \dot{\leftrightarrow}$ & $\stackrel{\infty}{=}$ & $\stackrel{\infty}{\Phi}$ & $\therefore$ & ஜ ま \\
\hline 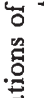 & 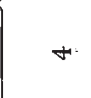 & அ $8 ஃ$ & $\stackrel{\mathcal{N}}{\dot{N}}$ & 穴灾芴 & $\stackrel{4}{\infty}$ & $\stackrel{\llcorner}{\dot{ \pm}}$ & 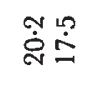 & $\mathscr{E}$ & 옴늉 & 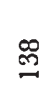 & $\stackrel{\varrho}{\rightleftarrows}$ \\
\hline కี & & $\stackrel{\infty}{2} 2 \infty$ & $\hat{\dot{\theta}}$ & $* * *$ & * & $*$ & $* *$ & $\hat{\varrho}$ & ชิ & 8 & 앙 \\
\hline & $\sim$ & চ品孚 & $\dot{\infty}$ & 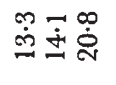 & $\stackrel{\sim}{\dot{\varphi}}$ & 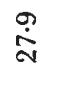 & 富 & $\bar{\delta}$ & 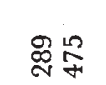 & $\Xi$ & 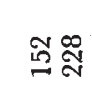 \\
\hline & - & m్ n్ & $\tilde{\sigma}$ & $\dot{\infty}$ & $\stackrel{\infty}{\dot{\Xi}}$ & $\dot{\Xi}$ & कृ & $\stackrel{\mathscr{্}}{\text { : }}$ & $\stackrel{\infty}{\mathbb{N}} \hat{\mathbb{N}}$ & $\stackrel{\infty}{=}$ & 옹요 \\
\hline & (总总 & 㟧 & & गั & & & कृ & & 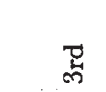 & & 㟧 \\
\hline & 氙. & ธี & & ્ָב & & & สี & & ָ & & ఫี \\
\hline & 造焉 & $\ddot{n}$ & & $\ddot{\Delta}$ & & 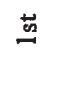 & & 节 & & $\ddot{\underline{a}}$ & \\
\hline 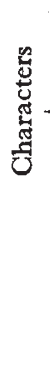 & 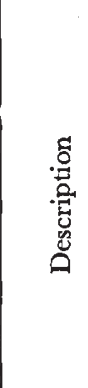 & 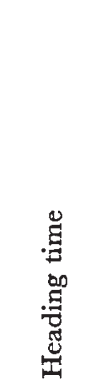 & 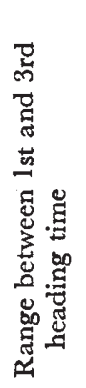 & 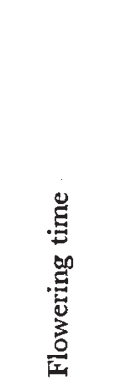 & 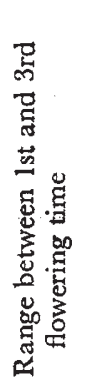 & $\begin{array}{l}7 \\
0 \\
0\end{array}$ & 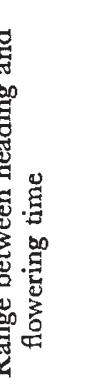 & & 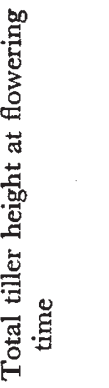 & & 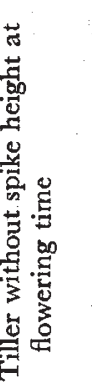 \\
\hline & ż & $-N m$ & $\psi$ & $\ln 0 N$ & $\infty$ & $a \subseteq$ & $=$ & & $\cong \quad$ & & $\mathscr{0}$ \\
\hline
\end{tabular}


COMPARISONS OF RELATED WHEAT SPECIES

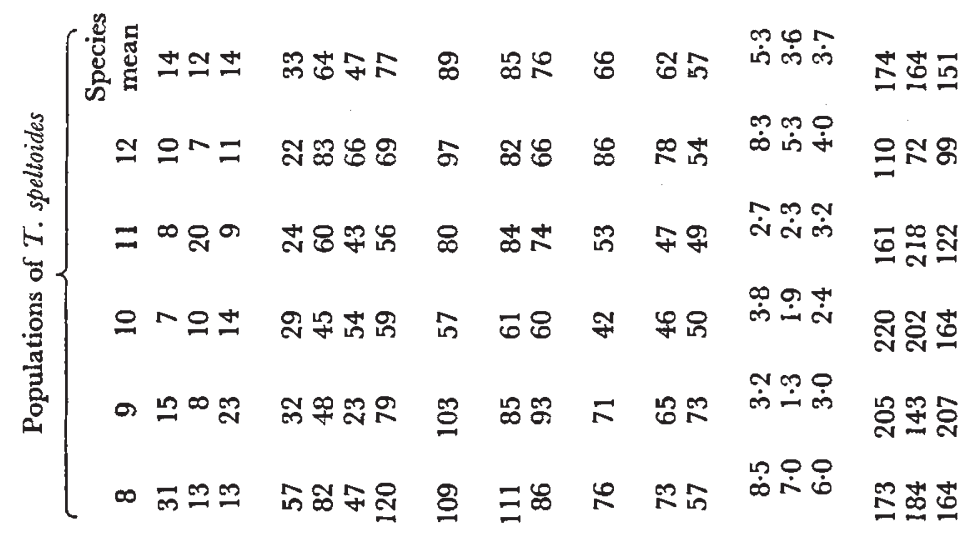

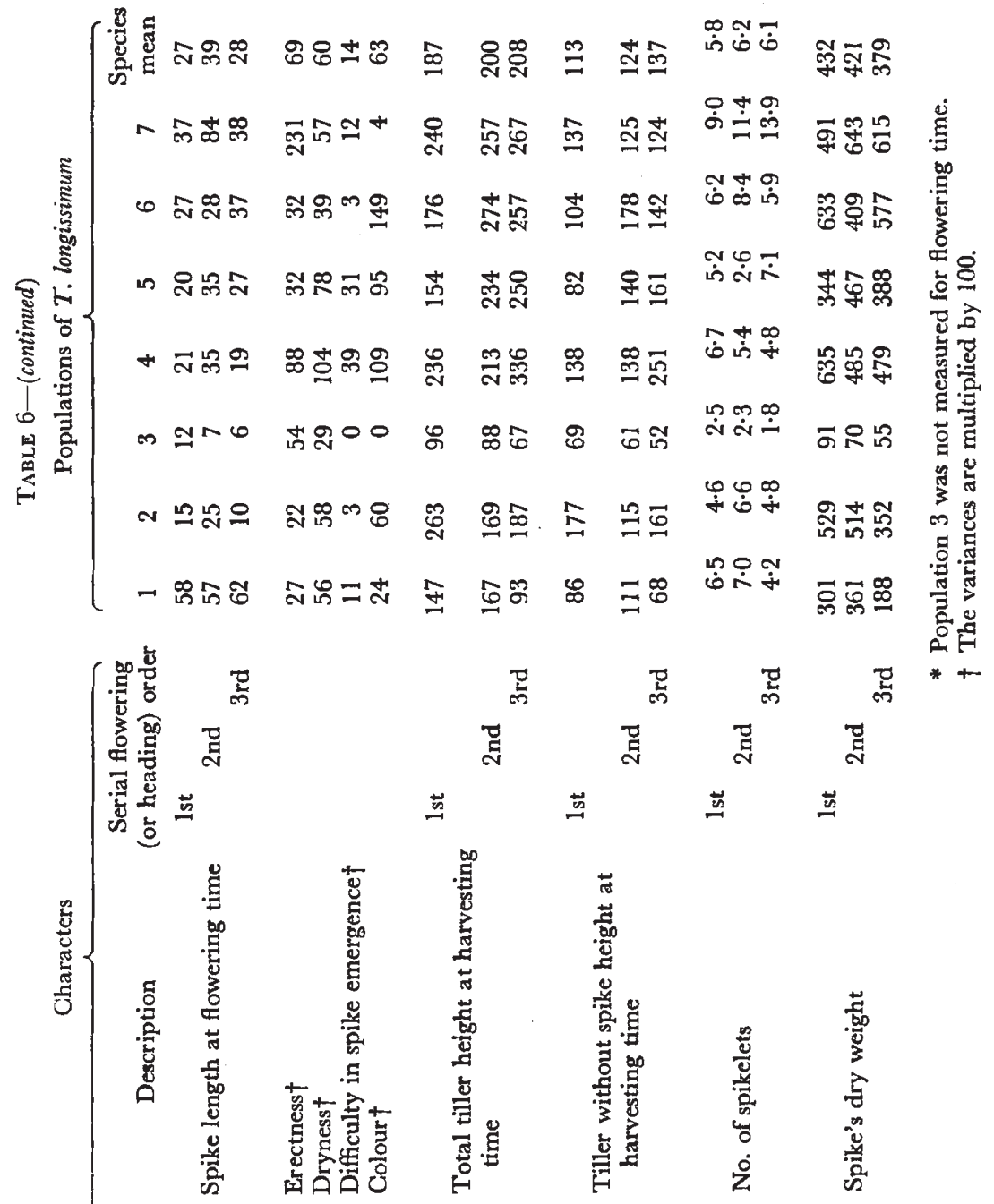

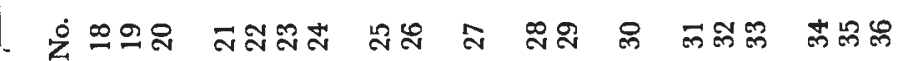


158 JOSEPH HILLEL, MARCUS W. FELDMAN, GIORA SIMCHEN
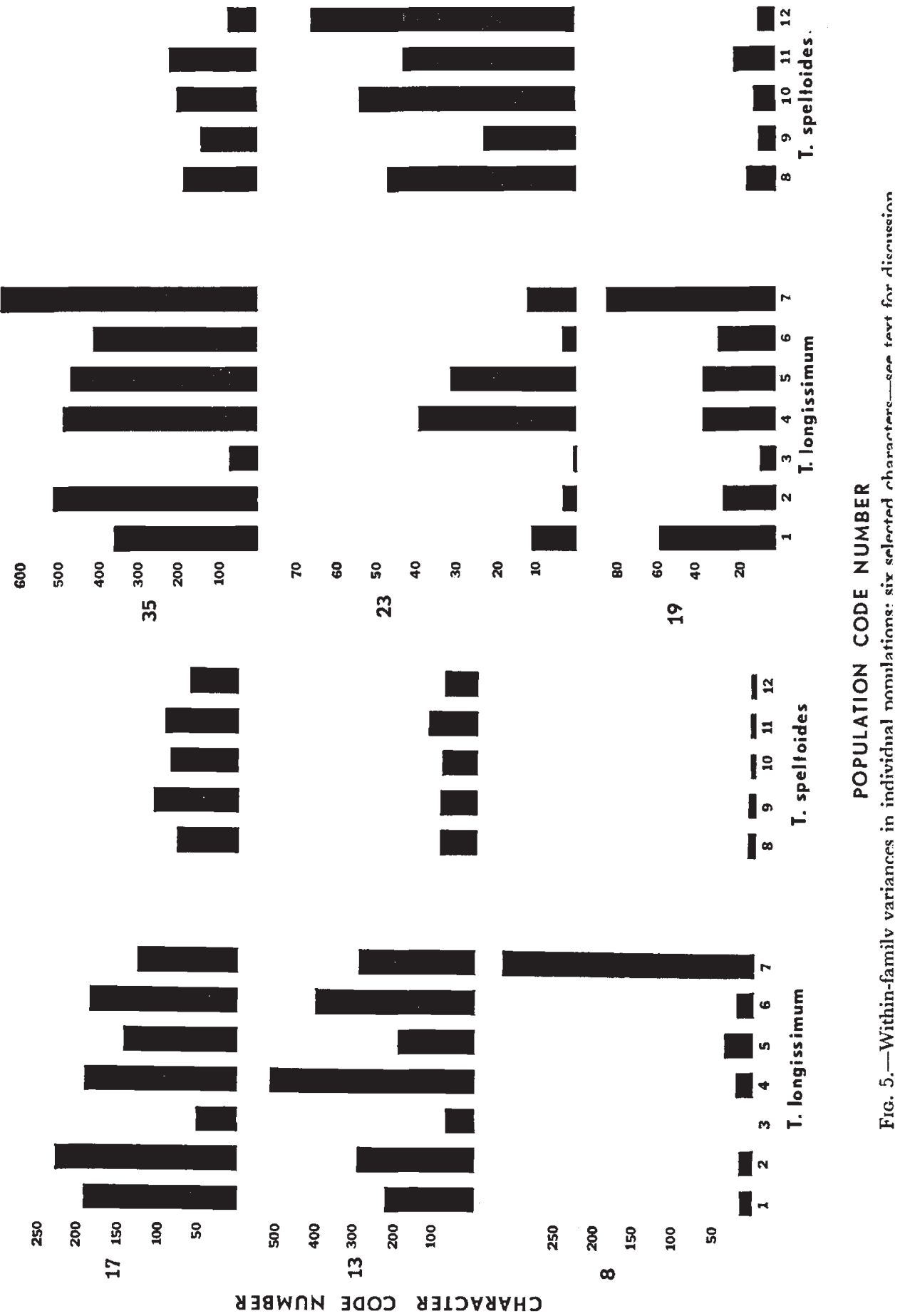
(a) In most of the characters the mean variances within families are higher in $T$. longissimum populations than in those of $T$. speltoides. As in the previous paragraph, the deviation from expectation is highly significant $\left(x^{2}=41.38, P<0.001\right)$. Fig. 6 , for ranking of the within-family variances, is analogous to fig. 4 for the total variances.

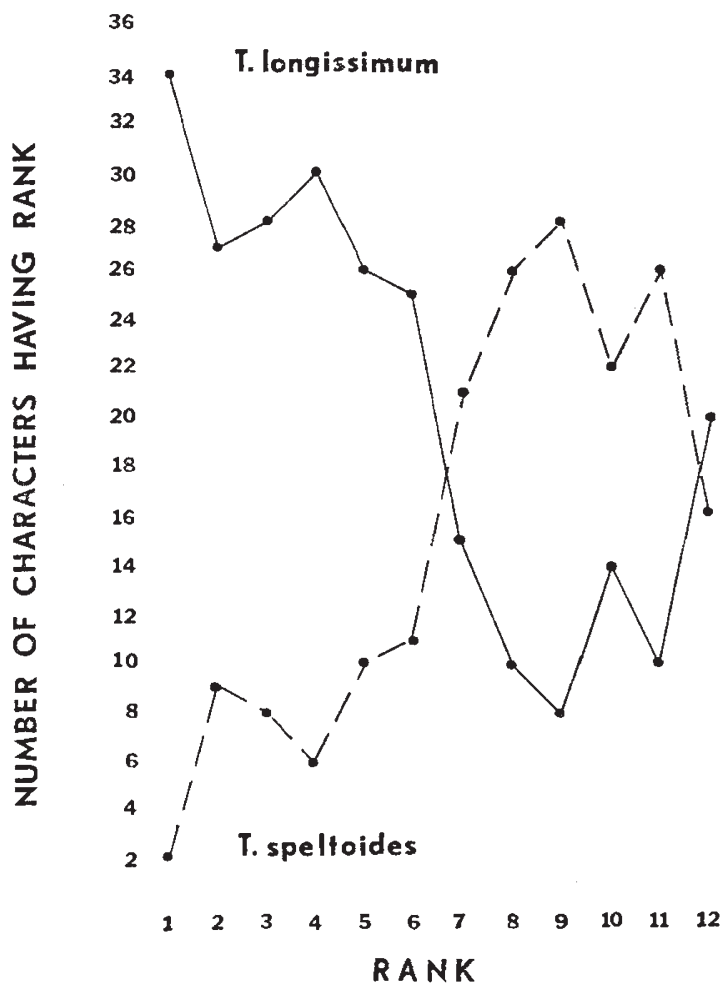

Fig. 6.-Summary of ranking of within-family variances for all 36 characters.

(b) Population 3 has the lowest values for the variances in most of the characters.

(c) Population 7 has exceptionally high values for the variances of flowering time (characters $5-11$ in table 6 and character 8 in fig. 5).

(d) The only character exhibiting clearly more variance in $T$. speltoides than in T. longissimum is difficulty of emergence (character 23 in table 6 and fig. 5). It should be noted that those spikes having most difficulty in emergence are nearly always devoid of viable seeds.

\section{(v) Correlations}

In table 7, two sets of correlations are presented. The first is correlation between population means and within family variances; these are seen in most cases to be insignificant. The second set of correlations is between population means of plants from the $S_{0}$ and the $S_{1}$ generations. These are seen to be extremely high, especially in T. longissimum. 
TABLE 7

Correlations: Set 1. Between $S_{0}$ means and within-family variance

Set 2. Between $S_{0}$ means and $S_{1}$ means

\begin{tabular}{|c|c|c|c|c|}
\hline \multirow{2}{*}{$\begin{array}{c}\text { Character } \\
\text { No. }\end{array}$} & \multicolumn{2}{|c|}{ Set 1} & \multicolumn{2}{|c|}{ Set 2} \\
\hline & T. longissimum & T. speltoides & T. longissimum & T. speltoides \\
\hline 1 & n.s. & n.s. & $* * *$ & $* *$ \\
\hline 2 & n.s. & n.s. & $* * *$ & $* *$ \\
\hline 3 & n.s. & n.s. & $* * *$ & $* *$ \\
\hline 4 & $* * *$ & n.s. & $* *$ & n.s. \\
\hline 5 & - & n.s. & - & $*$ \\
\hline 6 & - & n.s. & - & $* *$ \\
\hline 7 & - & n.s. & - & $*$ \\
\hline 8 & - & $*$ & - & n.s. \\
\hline 9 & - & n.s. & - & $*$ \\
\hline 10 & - & n.s. & - & $*$ \\
\hline 11 & - & n.s. & - & $* *$ \\
\hline 12 & n.s. & n.s. & $* * *$ & $*$ \\
\hline 13 & n.s. & n.s. & $* * *$ & * \\
\hline 14 & n.s. & $*$ & $* * *$ & * \\
\hline 15 & n.s. & n.s. & $* * *$ & $*$ \\
\hline 16 & n.s. & n.s. & $* * *$ & n.s. \\
\hline 17 & $* *$ & n.s. & $* * *$ & n.s. \\
\hline 18 & n.s. & n.s. & $* *$ & n.s. \\
\hline 19 & n.s. & n.s. & $* *$ & n.s. \\
\hline 20 & n.s. & n.s. & $*$ & n.s. \\
\hline 21 & n.s. & n.s. & $*$ & n.s. \\
\hline 22 & n.s. & n.s. & $* * *$ & $*$ \\
\hline 23 & $* *$ & $*$ & n.s. & n.s. \\
\hline 24 & $* *$ & $*$ & $* *$ & $* *$ \\
\hline 25 & n.s. & n.s. & $* * *$ & $*$ \\
\hline 26 & n.s. & n.s. & $* * *$ & n.s. \\
\hline 27 & n.s. & n.s. & $* * *$ & $*$ \\
\hline 28 & n.s. & n.s. & $* * *$ & $*$ \\
\hline 29 & $*$ & n.s. & $* * *$ & n.s. \\
\hline 30 & n.s. & n.s. & n.s. & $*$ \\
\hline 31 & n.s. & n.s. & $* * *$ & $* *$ \\
\hline 32 & n.s. & n.s. & $* * *$ & n.s. \\
\hline 33 & n.s. & n.s. & $* *$ & n.s. \\
\hline 34 & $*$ & $*$ & $* * *$ & $* *$ \\
\hline 35 & n.s. & n.s. & $* * *$ & $* *$ \\
\hline 36 & $*$ & n.s. & $* * *$ & $*$ \\
\hline $\begin{aligned} \text { n.s. } & =\mathrm{N} \\
* & =\mathrm{C} \\
* * & =\mathrm{C} \\
* * * & =\mathrm{C}\end{aligned}$ & $\begin{array}{l}\text { ynificant correl } \\
\text { tion significan } \\
\text { tion significan } \\
\text { tion significan }\end{array}$ & $\begin{array}{l}\text { ion. } \\
\cdot 01<P \leqslant 0 \\
001<P \leqslant 0 \\
P 0 \cdot 001\end{array}$ & & \\
\hline
\end{tabular}

\section{THEORETICAL CONSIDERATIONS}

(i) Population variances

In the experiments described above, the total variance within the populations may be partitioned into between- and within-family variances. The total variance calculated from the experiment represents an estimate of the total variance of the population in the wild one generation following the original sampling. Assuming the wild population to be in equilibrium we can therefore use the total variance in the experiment for inference on the 
variance of the original wild population. The experimental variance between families corresponds, in the wild population, to that part of the total variance produced by differences between the groups of descendants from different mother plants. In the wild population, corresponding to the within family, experimental variance would be that part of the total variance arising from the mean differences between individuals coming from the same mother plant.

Thus in a situation of 100 per cent. selfing it would be correct to extrapolate from high experimental variances between families to a considerable genetic diversity among mother plants in the wild. But in a mixed mating system, which is probably the most common situation, there is no control over the genotype of the pollen donor, and the inferences to the genetic diversity in the wild become more complex.

It is possible to derive a one-locus theory for hypothetical circumstances under which we might expect greater total variance from a selfing population than in an outcrossing population. The difficulties involved in extending this type of analysis to multi-locus quantitative characters are well known and discussed, for example, by Mather and Jinks (1971). Consider a character for which the genotypes $A A, A a$ and $a a$ contribute $d, h$ and $-d$ respectively $(d>0)$. Hillel, Simchen and Jinks (1972) have shown that if $u$ is the frequency of $A, v=1-u$ that of $a$ and $f$ the inbreeding coefficient, the total variance is

$$
2 u v(1+f) d^{2}+2 u v(1-f)[1-2 u v(1-f)] h^{2}-4 u v(1-f)(u-v) d h .
$$

We can therefore compare the total variances in two populations with inbreeding coefficients $f_{1}$ and $f_{2}$ respectively. The difference between the two till be

$$
\begin{aligned}
&\left(f_{1}-f_{2}\right) 2 u v d^{2}\left\{1-\frac{h^{2}}{d^{2}}-\frac{2 h}{d}+u\left[\frac{4 h}{d}+\frac{2 h^{2}}{d^{2}}\left(2-f_{1}-f_{2}\right)\right]\right. \\
&\left.-2 u^{2} \frac{h^{2}}{d^{2}}\left(2-f_{1}-f_{2}\right)\right\} .
\end{aligned}
$$

The situation of most interest to us is one in which $f_{1}$ is quite close to one and $f_{2}$ in the region of $0 \cdot 15-0.25$ so that $f_{1}-f_{2}>0$. The population with higher inbreeding will therefore have greater total variance provided

$$
1-\frac{h^{2}}{d^{2}}-\frac{2 h}{d}+u\left[\frac{4 h}{d}+\frac{2 h^{2}}{d^{2}}\left(2-f_{1}-f_{2}\right)\right]-2 u^{2} \frac{h^{2}}{d^{2}}\left(2-f_{1}-f_{2}\right)>0 .
$$

In analysing this quadratic equation for $u$, we note first that (3) is always true if $0<\frac{h}{d}<\sqrt{ } 2-1 \approx 0.414$, so that in these cases, for all gene frequencies $u$, the inbreeder will have greater total variance.

As $h / d$ increase, (3) indicates for which gene frequencies the inbreeder will have greater total variance. Thus if $h / d=1,(3)$ is true for $u>0.38$; while if $h / d=2$, the requirement is $u>0 \cdot 65$. As $h / d$ increases, $u$ must also increase to validate (3). The situation is represented graphically in fig. 7 . Note that when $f_{1}$ is close to one (as we suspect is the case in $T$. longissimum) and $f_{2}$ is relatively small (probably near 0.2 in $T$. speltoides) the situation is almost the same as that when $f_{1}=1$ and $f_{2}=0$, except for the factor 


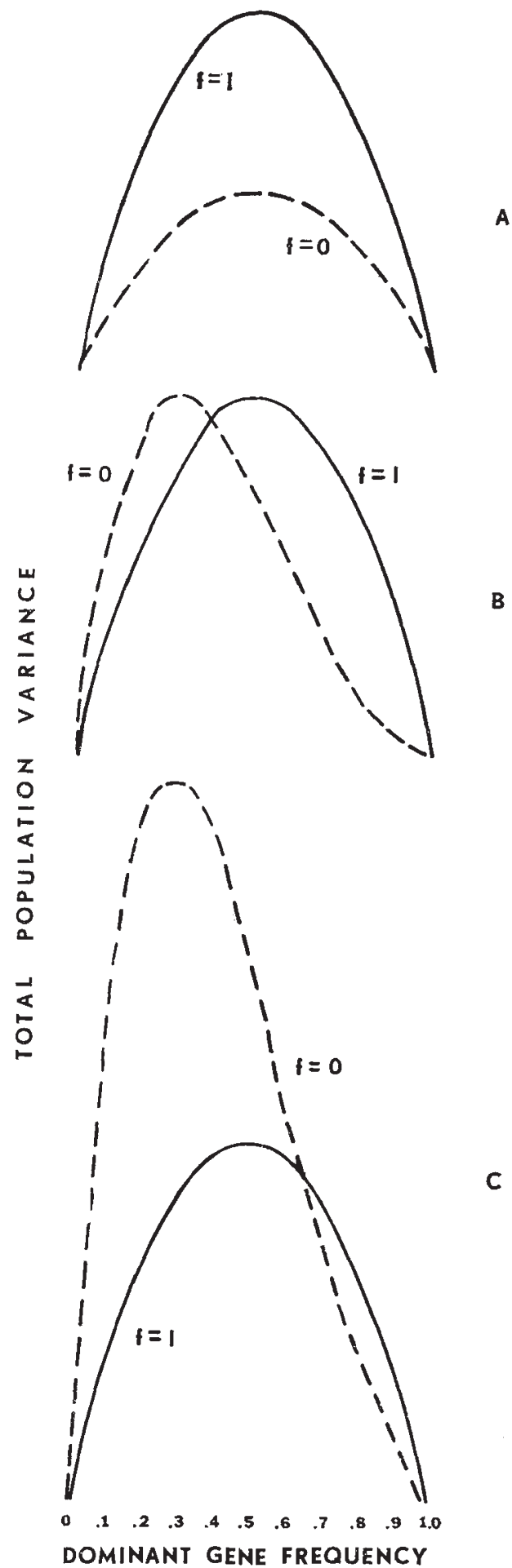

Fig. 7. The expected total population variance for a given $d$ as a function of dominant gene frequency for the absolute selfing situation $(f=1)$ and for complete random mating $(f=0)$. The function is described in the figure for three dominance ratio values: (A) $\frac{h}{d}=0$, no dominance; (B) $\frac{h}{d}=1$, complete dominance; (C) $\frac{h}{d}=\sqrt{2}$, over dominance. 
$\left(f_{1}-f_{2}\right)$. As $f_{1}$ and $f_{2}$ approach one another the difference between the systems vanishes.

If $h<0$, then instead of analysing (3) as a function of $u$, we treat it as a function of $v$ and, using $|h|$ instead of $h$, the above analysis gets a comparable form, with $v$ the frequency of the dominant allele.

Qualitatively then, when the dominant allele is in high enough frequency (how high will be determined by how dominant it is), the inbreeding population will have a greater total variance than the outcrosser. Alternatively, if the total variance in the selfer is higher than in the outcrosser, the dominant allele is probably the more frequent.

\section{(ii) Within-family variances}

The theoretical treatment of the within-family variance is more difficult than the treatment given above for the total variance. For most calculations we use the theory derived by Hillel et al. (1972), without repeating the detailed derivations presented there. The basic problem we are confronted with is whether it is correct to infer from high within family variances a high heterozygote frequency.

First, consider the within-family variance for a single-locus situation as in the previous section, but with outcrossing only, so that $f=0$. In this case the within family variance can be shown (using the same notation as above) to be

$$
V=\beta\left\{3 / 4\left(d^{2}+h^{2}\right)-h[\beta h / 2+3(u-v) d / 2]\right\}
$$

where $\beta=2 u v$ is the heterozygote frequency. Obviously, if $h=0, V$ is proportional to $\beta$. However, when $h \neq 0$ the dependence of the variance on the heterozygote frequency is confounded by the $(u-v)$ term in (4). The dependence of the variance on $\beta$ is shown in fig. 8. It is seen that relatively high variance can occur either for low or high heterozygote frequencies. For example, when $h / d=1$, with $d^{2}=100$, the same value $V=60$ is obtained at $\beta=0.25$ and $\beta=0.5$. One cannot, therefore, equate high heterozygosity with high variance.

The above remarks indicate that it is unwise to extrapolate from withinfamily variances to heterozygote frequencies. However, we may ask directly whether simple models can predict cases in which the within-family variance in a predominantly selfing species can be greater than in an outcrosser. Obviously, with pure selfing (at equilibrium) there is no within family variance. We chose inbreeding coefficients of $f=0.9$ for the selfer and $f=0 \cdot 1$ for the outcrosser and substitute these into the formula of equation 2, table 4 of Hillel et al. (1972) to obtain variances $V_{1}$ and $V_{2}$, respectively. Following the arithmetic manipulations the difference between the two variances is

$$
\begin{aligned}
V_{1}-V_{2}=u v\{ & \left.-1 \cdot 238 d^{2}-1 \cdot 142 h^{2}+1.484 d h\right\} \\
& +u^{2} v^{2}\left[1.214 h^{2}-2.428 d h\right] \\
& +0.067 u v(u-v) d h
\end{aligned}
$$

which can never be positive. It appears, therefore, that for the values of $f$ we believe to be relevant to our cases, the selfer cannot have a higher withinfamily variance than the outcrosser, when selection is assumed to be absent 
Can heterozygote advantage alter the conclusion from (5) and produce more variance in the selfer than in the outcrosser? First, without considering variances, let us compare two populations, one a pure selfer, in which the genotypes $A A, A a$, aa have fitnesses $x: 1: x$, respectively, and the other a pure outcrosser in which the fitnesses are $y: 1: y$. Obviously, $x<1 / 2$ is a prerequisite for polymorphism in the selfer (Allard et al., 1967; Karlin, 1968).

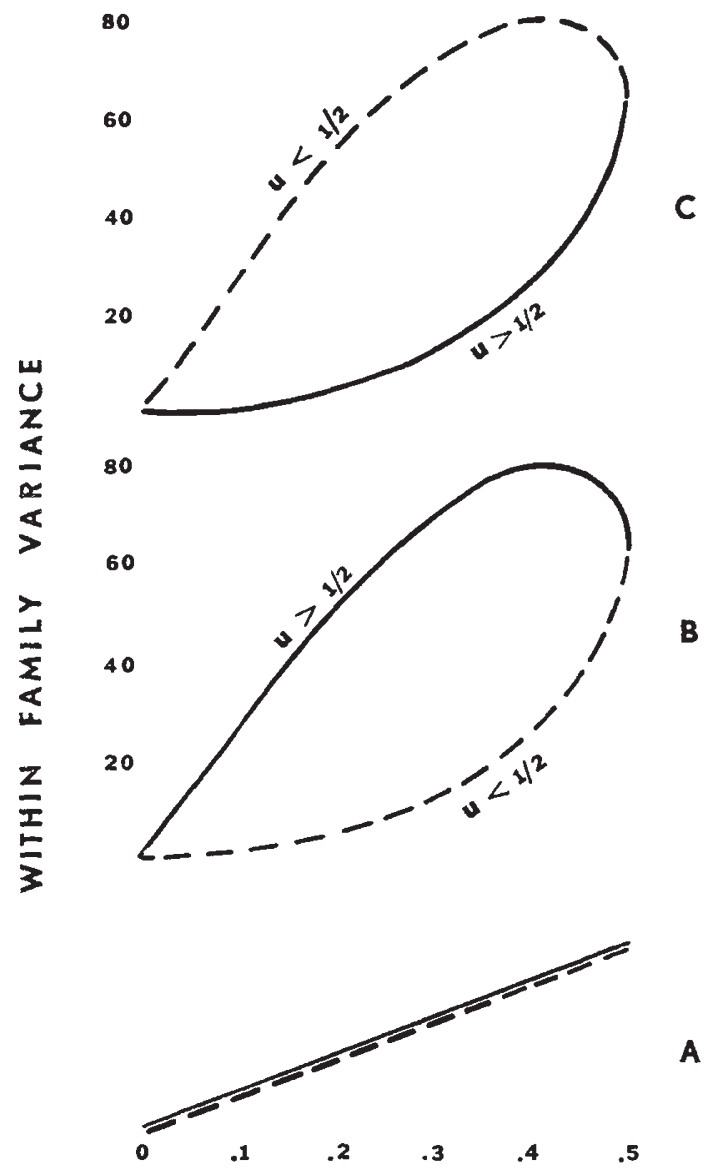

HETEROZYGOTE FREQUENCY

Frg. 8. -Within-family variance $v$, as a function of heterozygote frequency. $u=$ gene frequency of $A$. $A A, A a$ and aa contribute $d, h,-d$, respectively. (A) $h=0$, (B) $h=d$, (C) $h=-d$.

If $x<1 / 3$ and $y>x /(1-2 x)$ there are more heterozygotes at equilibrium in the selfer than in the outcrosser. For example, if $x=0.3$ then $y$ must be greater than 0.75 , while if $x=0 \cdot 2, y$ must be greater than 0.33 . Under these stringent selection conditions, therefore, more heterozygotes can occur in the selfer.

We now ask if, under the same selection conditions as in the previous paragraph but with $x<1 / 2$ so that the selfer is in polymorphic equilibrium, the within-family variance for a character whose values are $d, h$ and $-d$ as 
before, can be greater in the selfer. It is not difficult to show that under these conditions the mean within-family variance for the selfer is

$$
V_{1}=\frac{x(1-2 x) d^{2}}{(1+x)(1-x)}+\frac{x(1-2 x) h^{2}}{(1+x)^{2}(1-x)}
$$

and for the outcrosser

$$
V_{2}=\frac{y(1+2 y)}{(1+y)^{3}} d^{2}+\frac{y}{(1+y)^{2}} h^{2} .
$$

Hence $V_{1}-V_{2}>0$ when

$$
\frac{h^{2}}{d^{2}}\left[\frac{x(1-2 x)}{(1+x)^{2}(1-x)}-\frac{y}{(1+y)^{2}}\right]+\left[\frac{x(1-2 x)}{(1+x)(1-x)}-\frac{y(1+2 y)}{(1+y)^{3}}\right]>0 .
$$

Numerical examination of (8) suffices to show that the inequality is true for moderate $(h / d)$ values only when $x$ and $y$ are small, with $y$ smaller than $x$. When $h=0$ and $x=y$ in the range 0.15 through 0.35 , (8) holds. The general conclusion is that selection in favour of heterozygotes is required to be extremely strong and in most cases it must be even stronger in the outcrosser than the selfer.

\section{Discussion}

For the 36 quantitative characters investigated here it has been demonstrated that a great amount of variability exists in the selfing populations. In fact, there are higher total variances, higher variances between populations, and higher within-family variances in the selfer $\mathcal{T}$. longissimum than in the outcrosser $T$. speltoides.

With reference to the statistical analysis made, we can discount that the $F$ values are artifacts of scaling since most correlations between means and within-family variances were found to be insignificant (table 7). It cannot be argued that the variances we observe are due to environmental factors characteristic to the populations of the two species, because all the plants were grown in the same experimental field. The high correlations between the means of the $S_{0}$ and $S_{1}$ generations (table 7) further support a genetic interpretation of the results. Of course, this is not to say that genotypeenvironment interactions do not exist.

Population 3 of $T$. longissimum is a notable exception to the general trend of the results. This population is located (see table l, fig. 1) on the edge of a desert area. The climate is harsh but very consistent. The population size is estimated to be no larger than 500 plants, the smallest of all of our populations. The plants were less vigorous than those from other sites. It is possible that the consistency of the environment has determined the short-term strategy of high homozygosity with long-term variability being provided by the infrequent outcrossing events. Population 7 comes from the area with the next lowest rainfall to population 3 (see table 1), yet has a high withinfamily variability, particularly for flowering time. In our experience of the past few years the climate in this area has been very variable. If this is a genuine characteristic of the environment it may have mediated the production and maintenance of this variability.

There is no difficulty in explaining the greater differences between populations of $T$. longissimum than between populations of $T$. speltoides. 
Presumably, it is due to the low probability of a successful gene flow in T. longissimum, with each isolated population adapted to the specific conditions in its locality. Table 1 details the wide range of environments in which the populations of $T$. longissimum are found. The environments of the populations of $\mathcal{T}$. speltoides, on the other hand, do not differ greatly from one another.

The theoretical arguments for a character controlled by a single locus (Section 4) produced the conclusion that when the dominant allele is in a sufficiently high frequency, the inbreeder will have a greater total variance, the cut-off point depending on the degree of dominance. Our attempts to develop a corresponding theory to explain the finding that the within-family variances are higher in the selfer than in the outbreeder, can be regarded as unsuccessful unless one accepts the possibility of extremely high heterozygote advantage in both $\mathcal{T}$. longissimum and $\mathcal{T}$. speltoides. Had there existed such strong selection, substantial differences would have been expected between the means of the $S_{0}$ and $S_{1}$ generations. These were not observed, so the theory does not appear to cope adequately with the existence of high withinfamily variances. Further experimental and theoretical studies are planned in the hope of elucidating what lies behind this surprising result.

\section{REFERENGES}

ALLARD, R. W. 1965. Genetic systems associated with colonizing ability in predominantly self-pollinated species. In The Genetics of Colonizing Species, pp. 50-76 (ed. H. G. Baker and G. L. Stebbins). Academic Press, New York.

ALlARD, R. W., JAIN, s. K., AND WORKMAN, P. L. 1967. The genetics of inbreeding populations. Adv. in Genet., 14, 55-131.

ANTonovics, J. 1968. Evolution in closely adjacent plant populations. V. Evolution of self-fertility. Heredity, 23, 219-238.

BOWDEN, w. м. 1959. The toxonomy and nomenclature of the wheats, barleys, and ryes and their wild relatives. Can. 7. Botany, 37, 657-684.

CHENNAVEeraiah, M. s. 1960. Kariomorphologic and cytotaxonomic studies in Aegilops. Acta Horti Gotoburgenesis, 23, 85-178.

HAYMAN, B. I. 1953. Mixed selfing and random mating when homozygotes are at a disadvantage. Heredity, 7, 185-192.

HAYMAN, в. I., AND MATHER, к. 1953. The progress of inbreeding when homozygotes are at a disadvantage. Heredity, 7, 165-183.

HILLEL, J., SIMGHEN, G., AND JINKS, J. L. 1972. Generalised selfing series as an experimental design. I. Theory. Theor. Pop. Biol., 3, 466-490.

IMAM, A. G., AND ALLARD, R. W. 1965. Population studies in predominantly self-pollinated species. VI. Genetic variability between and within natural populations of wild oats from differing habitats in California. Genetics, 51, 49-62.

JAIN, s. K., AND ALlARD, R. w. 1966. The effects of linkage, epistasis and inbreeding on population changes under selection. Genetics, 53, 633-659.

JAIN, s. K., AND MARSHAL, D. R. 1967. Population studies in predominantly self-pollinating species. X. Variation in natural populations of Avena fatua and A. barbata. Amer. Natur., 101, 19-33.

JAIN, S. K., MARSHAL, D. R., AND WU, K. 1970. Genetic variability in natural populations of softeless (Bromus Mollis L.). Evolution, 23, 649-659.

JONEs, м. E. 1971a. The population genetics of Arabidopsis thaliana. I. The breeding system. Heredity, 27, 39-50.

Jones, м. E. $1971 b$. The population genetics of Arabidopsis thaliana. II. Population structure. Heredity, 27, 51-58.

KARLIN, s. 1968. Equilibrium Behavior of Population Genetic Models with Non-Random Mating. Gordon and Breach, London.

KNOWLES, P. F. 1943. Improving an annual bromegrass, Bromus mollis L., for range purposes. 7. Am. Soc. Agron., 35, 584-594. 
LAWRENCE, M. J. 1969. Variation in wild populations of Papaver dubium. II. Variation between populations. Heredity, 24, 337-345.

LEWIS, K. R., AND John, B. 1963. Chromosome Marker. Churchill, London.

MACKEY, J. 1968. Relationships in the Triticinae. Third International Wheat Genetic Symposium, Australian Academy of Sciences. Canberra.

MATHER, K., AND JINKS, J. L. 1971. Biometrical Genetics, Second edition. Chapman Hall, London.

MOORE, D. M., AND LEWIS, H. 1965. The evolution of self-pollination in Clarkia xantiana. Evolution, 19, 109-114.

MORRIS, R., AND SEARS, E. R. 1967. The cytogenetics of wheat and its relatives. In Wheat and Wheat Improvement, pp. 19-87 (ed. K. S. Quinesberry and L. P. Reitz). Am. Soc. Agron.

PARSONS, P. A. 1957. Selfing under conditions favoring heterozygosity. Heredity, 11, 411421.

PEDERSON, D. G. 1968. Environmental stress, heterozygote advantage and genotypeenvironment interaction in Arabidopsis. Heredity, 23, 127-138.

SEARs, E. R. 1969. Wheat cytogenetics. Annual Review of Genetics, 3, 451-468.

SIMCHEN, G., ZARCHI, Y., AND HILLEL, J. 1971. Supernumerary chromosomes in the second outbreeding species of the wheat group. Chromosoma, 33, 63-69.

WEIL, J., AND ALLARD, R. W. 1964. The mating system and genetic variability in natural populations of Collinisia heterophylla. Evolution, 18, 515-525.

ZARCHI, Y., SIMCHEN, G., HILLEL, J., AND SCHAPP, T. 1972. Chiasmata and the breeding system in wild populations of diploid wheats. Chromosoma, 38, 74-94.

zOHARY, D. 1966. The evolution of genomes in Aegilops and Triticum. Hereditas (Lund), Suppl. 2, 207-217.

ZOHARY, D., AND IMBER, D. 1963. Genetic dimorphism in fruit types in Aegilops speltoides. Heredity, 18, 223-231. 